\title{
PROFESSORES DA EDUCAÇÃO BÁSICA ESTÃo APTOS A PRESTAR PRIMEIROS SOCORROS?
}

\author{
ARE TEACHERS OF PRIMARY EDUCATION ABLE TO PROVIDE FIRST AID?
}

\author{
Danielle Xavier Moraes ${ }^{1}$ Jessica de Oliveira Montebello ${ }^{2}$ Carmen Serrano Darc $^{3}$ Vanessa \\ Cindy Neres Lima ${ }^{4}$ André Luis Fernandes de Oliveira ${ }^{5}$ Isabela Vieira Damas Rocha ${ }^{6}$ \\ Jacqueline Andréia Bernardes Leão Cordeiro ${ }^{7}$ Hélio Galdino Júnior ${ }^{8}$
}

\begin{abstract}
RESUMO
Objetivo: Identificar qual conhecimento que os professores da educação básica possuem sobre primeiros socorros. Métodos: Estudo bibliográfico, descritivo, tipo revisão integrativa realizado entre maio e julho de 2020 com artigos dos últimos cinco anos das bases de dados PubMed, SciELO e LILACS acessadas pela Biblioteca Virtual em Saúde (BVS) utilizando os descritores em Ciências da Saúde "primeiros socorros" e "professores" em português e inglês. Resultados: Foram incluídos neste estudo 40 artigos. Em geral, os conhecimentos dos professores foram baixos e insuficientes. No entanto, mais de $70 \%$ deles gostariam de aprender sobre o tema. Profissionais da saúde como fontes de conhecimento foram pouco referidos. Os estudos abordaram primeiros socorros a diferentes situações como acontecimentos gerais, epilepsia/convulsões, traumatismo/avulsão dentária, entre outros. Conclusões: Foi predominante o baixo nível de conhecimento sobre primeiros socorros entre professores da educação básica evidenciando necessidade de investimentos na formação de professores no assunto e na parceria saúde-educação para promover ambientes escolares seguros.

Palavras-chave: Primeiros Socorros; Professores; Educação Básica; Conhecimento; Educação em Saúde.
\end{abstract}

\begin{abstract}
Objective: Identify what knowledge primary education teachers have about first aid. Methods: A bibliographic, descriptive, integrative review study conducted between May and July, 2020 with articles from the last five years of PubMed, SciELO and LILACS databases, accessed by the Biblioteca Virtual em Saúde (BVS) using the descriptors in Health Sciences: "first aid" and "teachers" in Portuguese and English. Results: 40 articles were included in this study. In general, teachers' knowledge was low and insufficient. However, more than $70 \%$ of them would like to learn about the subject. Health professionals as sources of knowledge were barely mentioned. The studies addressed first aid to different situations such as general events, epilepsy/convulsions, dental trauma/avulsion, among others. Conclusions: The low level of knowledge about first aid among basic education teachers was predominant, showing the need for investments in teacher's training on the subject and in the health-education partnership to promote safe school environments.
\end{abstract}

Keywords: First Aid; School Teachers; Schools; Knowledge; Health Education.

\footnotetext{
${ }^{1}$ Graduanda em Enfermagem pela Faculdade de Enfermagem da Universidade Federal de Goiás - FEN/UFG, Goiânia, Brasil. Atualmente bolsista do Programa de Educação Tutorial (PET) Enfermagem UFG. ORCID: https://orcid.org/0000-0001-8310-9287

${ }^{2}$ Graduanda em Enfermagem pela Faculdade de Enfermagem da Universidade Federal de Goiás - FEN/UFG, Goiânia, Brasil. Atualmente bolsista do Programa de Educação Tutorial (PET) Enfermagem UFG. ORCID: https://orcid.org/0000-0002-1317-7927

${ }^{3}$ Graduanda em Enfermagem pela Faculdade de Enfermagem da Universidade Federal de Goiás - FEN/UFG, Goiânia, Brasil. Egressa do Programa de Educação Tutorial (PET) Enfermagem UFG. ORCID: https://orcid.org/0000-0002-3501-2859

${ }^{4}$ Graduanda em Enfermagem pela Faculdade de Enfermagem da Universidade Federal de Goiás - FEN/UFG, Goiânia, Brasil. Egressa do Programa de Educação Tutorial (PET) Enfermagem UFG. ORCID: https://orcid.org/0000-0003-2123-6437

${ }^{5}$ Graduando em Enfermagem pela Faculdade de Enfermagem da Universidade Federal de Goiás - FEN/UFG, Goiânia, Brasil. Atualmente bolsista do Programa de Educação Tutorial (PET) Enfermagem UFG. ORCID: https://orcid.org/0000-0003-4620-4538

${ }^{6}$ Graduanda em Enfermagem pela Faculdade de Enfermagem da Universidade Federal de Goiás - FEN/UFG, Goiânia, Brasil. Egressa do Programa de Educação Tutorial (PET) Enfermagem UFG. ORCID: https://orcid.org/0000-0002-3494-9906

${ }^{7}$ Enfermeira. Doutora em Enfermagem, docente da Faculdade de Enfermagem da Universidade Federal de Goiás - FEN/UFG, Goiânia, Brasil.

Coordenadora da Liga de Urgência, Trauma e Emergência (LUTE). ORCID: https://orcid.org/0000-0003-0703-3609

${ }^{8}$ Enfermeiro. Doutor em Medicina Tropical e Saúde Pública, docente da Faculdade de Enfermagem da Universidade Federal de Goiás - FEN/UFG,

Goiânia, Brasil. Tutor do Programa de Educação Tutorial (PET) Enfermagem UFG. ORCID: https://orcid.org/0000-0002-5570-8183
} 


\section{INTRODUÇÃO}

Acidente é todo acontecimento não intencional que pode provocar uma lesão corporal ou perturbação reconhecível, podendo causar sequelas permanentes ou temporárias, ou até mesmo a morte ${ }^{(1)}$. Os primeiros socorros são atendimentos temporários e imediatos de pessoas que se encontram feridas ou que manifestam sinal súbito com risco de morte. Nesse atendimento, é necessário saber reconhecer as situações que colocam a vida em risco e tomar as atitudes necessárias para manter a vítima viva e na melhor condição possível até que chegue atendimento especializado ${ }^{(2)}$.

Os mais variados locais estão sujeitos às ocorrências de acidentes, e o ambiente escolar é um local propício para a ocorrência deles devido à grande quantidade de crianças que nele se encontram, principalmente quando se fala da educação primária, e das diferentes atividades que são desenvolvidas as quais envolvem interações em grupos, práticas esportivas e motoras $^{(3,4)}$.

Uma vez que acidentes ocorrem em uma diversidade de locais e com os mais variados públicos, as pessoas que prestam os primeiros socorros à vítima devem ter habilidades para executá-los corretamente pois, os cuidados prestados de forma inadequada podem agravar o quadro das vítimas do acidente $^{(4)}$. Os professores, por serem os indivíduos mais próximos às crianças acidentadas no ambiente escolar, necessitam de noções sobre primeiros socorros, uma vez que muitas vidas podem ser salvas, traumas e sequelas minimizadas quando o socorro é prestado de imediato ${ }^{(5)}$.

A morte de Lucas Begalli, por asfixia durante um passeio escolar, ocasionada por engasgo com um pedaço de salsicha do cachorro quente, levantou debates que culminou no sancionamento em 2018 da lei intitulada de Lei Lucas - Lei $\mathrm{N}^{\circ} 13.722$, de 4 de outubro de 2018, que designa aos estabelecimentos de ensino de educação básica da rede pública e da rede privada a necessidade de capacitar professores e funcionários sobre primeiros socorros ${ }^{(6)}$.

Recente estudo realizado com profissionais de nível superior de sete escolas no estado do Mato Grosso, identificou que $43 \%$ destes profissionais nunca realizaram um treinamento sobre primeiros socorros, e no teste de conhecimento apresentaram média de acerto de 46,1\% mostrando déficit de conhecimento $^{(2)}$. Outros estudos apontam o despreparo em relação aos primeiros socorros, desde a formação do professor, o que corrobora para seu baixo conhecimento e dificuldade de prestar o socorro adequado ${ }^{(7,8)}$.

Diante deste contexto, os professores podem contribuir para salvar a vida de muitas crianças e adolescentes reduzindo a taxa de mortalidade e acidentes que ocorrem nesses locais ou, com condutas incorretas, potencializar os traumas sofridos pelos estudantes na tentativa de auxiliar na emergência, ou ainda, não prestar socorro. Assim, levantou-se a seguinte questão: qual o 
conhecimento que os professores de diferentes níveis educacionais possuem sobre primeiros socorros? A resposta a essa questão pode direcionar intervenções de capacitação e de formação de professores.

O objetivo deste estudo é identificar qual o conhecimento que os professores dos níveis de educação infantil, fundamental e médio possuem sobre primeiros socorros.

\section{MÉTODOS}

Trata-se de um estudo bibliográfico, descritivo, tipo revisão integrativa. Foram realizadas as etapas de identificação do tema e da questão norteadora; estabelecimento dos critérios inclusão e exclusão; seleção dos estudos que seriam incluídos por meio da leitura dos resumos; leitura exaustiva dos artigos selecionados na íntegra; interpretação dos resultados e apresentação do conhecimento $^{(9)}$.

A busca pelos artigos ocorreu nos meses de março a julho de 2020, baseada na questão norteadora "Qual o conhecimento dos professores dos níveis de educação infantil, fundamental e médio sobre primeiros socorros? ". As bases de dados utilizadas para busca foram Public Medical Literature Analysis and Retrieval System Online (PubMed), Scientific Electronic Library Online (SciELO) e Latin American and
Caribbean Health Sciences Literature (LILACS) acessadas por meio da Biblioteca Virtual em Saúde (BVS).

Os Descritores em Ciências da Saúde (DeCS) selecionados, respectivamente, em português e inglês foram: primeiros socorros e professores, este último sinônimo de docente, e first aid e teachers. Estes foram combinados com os operadores booleanos AND e aspas ("“), logo configurado da seguinte maneira: "primeiros socorros" AND "professores" e "first aid" AND "teachers".

Os critérios de inclusão foram aplicados a partir dos filtros disponibilizados nas próprias bases de dados sendo: artigos dos últimos 5 anos, texto completo e artigos disponíveis em inglês, português e espanhol.

Os critérios de exclusão foram: artigos que não respondiam à pergunta de pesquisa, editoriais, artigos de relato de experiência, artigos de revisão, dissertação e aqueles que apareciam mais de uma vez nas bases ou entre elas (duplicados). fluxograma da seleção dos artigos se encontra na Figura 1.

As informações dos estudos foram extraídas utilizando um formulário previamente elaborado pelos autores, condizente com os objetivos do estudo. 
Figura 1 - Fluxograma de seleção dos artigos para o estudo. Revisão integrativa, 2021.

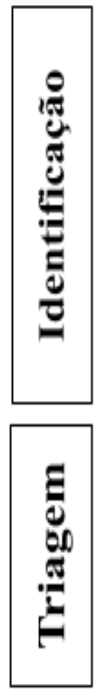

Estratégia de busca: "primeiros socorros" AND "professores" e "first aid" AND "teachers"
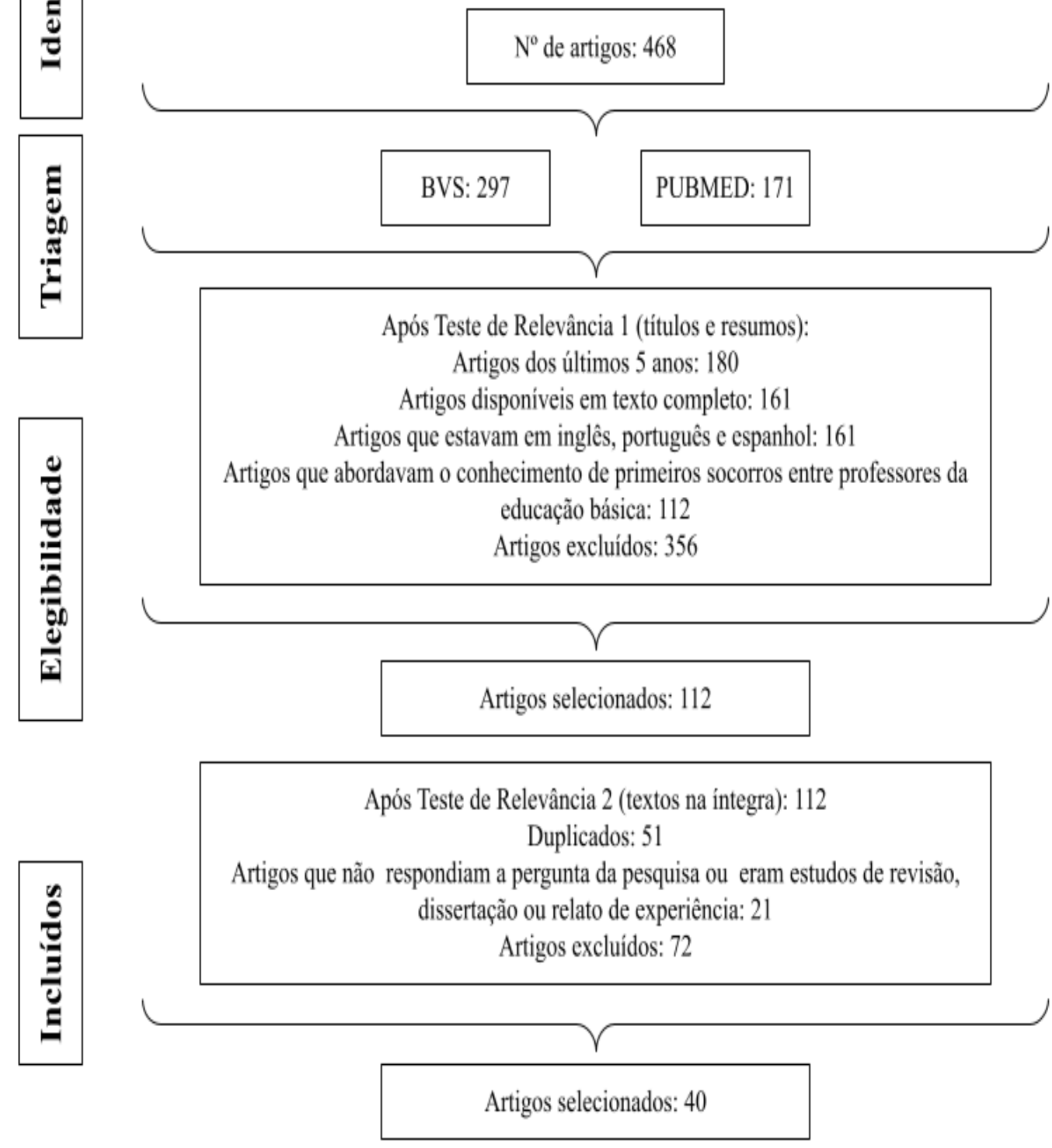

Fonte: Elaborada pelos autores (2021). 


\section{RESULTADOS}

O quadro 1 apresenta o quadro síntese dos 40 estudos incluídos ${ }^{(10-47)}$.

Quadro 1 - Quadro síntese dos artigos selecionados para o estudo. Revisão integrativa, 2021.

\begin{tabular}{|c|c|c|c|c|c|c|}
\hline Estudos/País & Autor/Ano & Objetivo & Metodologia & $\begin{array}{l}\text { Conhecimento em } \\
\text { Primeiros Socorros } \\
\text { (PS) }\end{array}$ & $\begin{array}{l}\text { Fonte do } \\
\text { conhecimento } \\
\text { sobre PS }\end{array}$ & Conclusão \\
\hline $\begin{array}{l}\text { E1/Arábia } \\
\text { Saudita }\end{array}$ & $\begin{array}{l}\text { Alqahtani, } \\
\mathrm{JM} / 2015^{10}\end{array}$ & $\begin{array}{l}\text { Investigar o } \\
\text { conheciment } \\
\text { o de } \\
\text { professores } \\
\text { do sexo } \\
\text { masculino no } \\
\text { sul da Arábia } \\
\text { Saudita e sua } \\
\text { prática para } \\
\text { estudantes } \\
\text { que têm } \\
\text { epilepsia }\end{array}$ & $\begin{array}{l}\text { Estudo transversal realizado com } 315 \\
\text { professores de } 30 \quad 30 \text { escolas } \\
\text { primárias/ensino fundamental e } 20 \\
\text { escolas intermediárias/ensino médio } \\
\text { por meio de aplicação de questionário } \\
\text { autoadministrado }\end{array}$ & $\begin{array}{lr}64,1 \% & \text { dos } \\
\text { professores } & \text { não } \\
\text { conseguiram prestar } \\
\text { PS diante de uma } \\
\text { crise e } 65,7 \% \text { não } \\
\text { estavam equipados } \\
\text { para isso. } 84 \% \\
\text { precisavam } \\
\text { informações sobre } \\
\text { epilepsia e } 86,7 \% \text { de } \\
\text { instruções sobre PS } \\
\text { nessas situações }\end{array}$ & $\begin{array}{l}\text { Amigos e parentes } \\
(36,8 \%), \quad \text { leitura } \\
(21,6 \%), \quad \text { mídia } \\
(20,6 \%) \text {, educação } \\
(14,6 \%) \quad \text { e } \\
\text { médicos }(6,3 \%)\end{array}$ & $\begin{array}{l}\text { Embora os } \\
\text { professores } \\
\text { tenham } \\
\text { conhecimento } \\
\text { sobre } \\
\text { condição, eles } \\
\text { têm dificuldade } \\
\text { em ajudar o } \\
\text { aluno em } \\
\text { convulsão. } \\
\text { Demonstraram } \\
\text { entusiasmo pelo } \\
\text { treinamento de } \\
\text { PS }\end{array}$ \\
\hline $\begin{array}{l}\text { E2/ Arábia } \\
\text { Saudita }\end{array}$ & $\begin{array}{lr}\text { Al } & \text { Aloola } \\
\text { NA, } & \text { Saba } \\
\text { M, } & \text { Nissen } \\
\text { L, } & \end{array}$ & $\begin{array}{l}\text { Desenvolver, } \\
\text { implementar } \\
\text { e avaliar os } \\
\text { efeitos de um }\end{array}$ & $\begin{array}{l}\text { Utilizou um "Programa de Ação } \\
\text { Escolar para Asma" (SAAP) entre } 47 \\
\text { professores nas escolas primárias de } \\
\text { meninas na Arábia Saudita. Foi }\end{array}$ & $\begin{array}{l}71 \% \text { dos professores } \\
\text { não tinham recebido } \\
\text { nenhuma educação } \\
\text { sobre asma. Antes }\end{array}$ & Não informado & $\begin{array}{l}\text { O SAAP teve } \\
\text { um efeito } \\
\text { positivo sobre os } \\
\text { níveis de }\end{array}$ \\
\hline
\end{tabular}


Alewairdhi programa

HA, educacional

Alaloola A, de asma na

Saini escola sobre

$\mathrm{B} / 2017^{11} \quad \mathrm{a}$

conscientizaç

ão e a

competência

dos

professores

das escolas

primárias

sauditas e

oferecer

intervenções

de PS

relacionados

à asma aplicado pré-teste/pós-teste. Usou-se do programa, 27\% um questionário de conscientização e estavam aptos para uma ficha de competência sobre asma cuidar de crianças para avaliação do programa com asma e após houve uma melhora significativa na consciência sobre a asma e em suas habilidades de PS, mas houve melhorias mínimas em suas atitudes e gestão da asma consciência

asma

participantes,

suas atitudes em relação à doença

competência em fornecer cuidados em PS para asma durante emergências nas escolas

\begin{tabular}{|c|c|c|c|c|c|}
\hline $\begin{array}{l}\text { E3/Arábia } \\
\text { Saudita }\end{array}$ & $\begin{array}{l}\text { Alsadhan } \\
\text { SA, } \\
\text { Alsayari } \\
\text { NF, } \\
\text { Abuabat } \\
\text { MF/2018 }\end{array}$ & $\begin{array}{l}\text { Avaliar o } \\
\text { conheciment } \\
\text { o sobre } \\
\text { lesões } \\
\text { dentárias } \\
\text { traumáticas e } \\
\text { seu manejo } \\
\text { entre } \\
\text { professores } \\
\text { do ensino } \\
\text { fundamental } \\
\text { em Riad, } \\
\text { Arábia }\end{array}$ & $\begin{array}{l}\text { Estudo transversal. Dados foram } \\
\text { coletados através de questionário } \\
\text { autoaplicável com } 1520 \text { professores de } \\
\text { escolas primárias públicas e privadas } \\
\text { nas cinco áreas geográficas da cidade } \\
\text { de Riyadh }\end{array}$ & $\begin{array}{l}\text { A pontuação do Não informado } \\
\text { professor indica um } \\
\text { nível muito baixo de } \\
\text { conhecimento sobre } \\
\text { o gerenciamento de } \\
\text { lesões dentárias } \\
\text { traumáticas nas } \\
\text { escolas. } 38,2 \% \\
\text { leram ou ouviram } \\
\text { falar sobre o assunto } \\
\text { e apenas 20,1\% } \\
\text { haviam aprendido } \\
\text { anteriormente sobre }\end{array}$ & 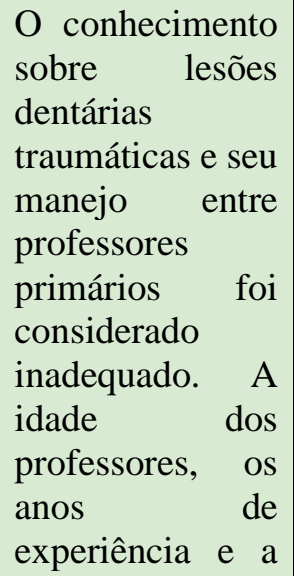 \\
\hline
\end{tabular}




\begin{tabular}{|c|c|c|c|c|c|c|}
\hline & & $\begin{array}{l}\text { Saudita e } \\
\text { efeitos de } \\
\text { gênero, } \\
\text { nacionalidad } \\
\text { e, estado } \\
\text { civil, tipo de } \\
\text { escola, área } \\
\text { geográfica, } \\
\text { faixa etária, } \\
\text { nível de } \\
\text { escolaridade } \\
\text { e anos de } \\
\text { experiência } \\
\text { no } \\
\text { conheciment } \\
\text { o deles }\end{array}$ & & $\begin{array}{l}\text { o gerenciamento } \\
\text { dessas } \\
\text { lesões.Apenas } \\
14,1 \% \text { estavam } \\
\text { satisfeitos com seus } \\
\text { conhecimentos } \\
\text { atuais }\end{array}$ & & $\begin{array}{l}\text { localização } \\
\text { geográfica da } \\
\text { escola } \\
\text { associaram-se ao } \\
\text { conhecimento } \\
\text { sobre o manejo } \\
\text { dessas lesões }\end{array}$ \\
\hline $\begin{array}{l}\text { E4/Arábia } \\
\text { Saudita }\end{array}$ & $\begin{array}{l}\text { Al-Harbi } \\
\text { AF, Alsaid } \\
\text { LA, } \\
\text { Parameasw } \\
\text { ari } \quad \text { PJ } \\
2018^{13}\end{array}$ & $\begin{array}{l}\text { Avaliar o } \\
\text { nível de } \\
\text { conheciment } \\
\text { o, atitude e } \\
\text { prática de } \\
\text { professoras } \\
\text { do ensino } \\
\text { fundamental } \\
\text { em relação a } \\
\text { estudantes } \\
\text { com } \\
\text { epilepsia em } \\
\text { Riyadh, } \\
\text { Arábia } \\
\text { Saudita. }\end{array}$ & $\begin{array}{l}\text { Estudo transversal. Foram distribuídos } \\
\text { aos professores } 630 \text { questionários auto } \\
\text { administrados. A taxa de resposta foi de } \\
92,4 \% \text {. }\end{array}$ & $\begin{array}{l}79,2 \% \text { eram cientes } \\
\text { da epilepsia, a } \\
\text { familiaridade dos } \\
\text { professores com o } \\
\text { assunto estava acima } \\
\text { da média. A prática } \\
\text { foi considerada } \\
\text { ruim, } 31,8 \% \text { sentiam } \\
\text { capazes de dar PS a } \\
\text { um aluno com } \\
\text { convulsão }\end{array}$ & Não informado. & $\begin{array}{l}\text { Notou-se um } \\
\text { conhecimento } \\
\text { acima da média } \\
\text { sobre epilepsia, } \\
\text { porém ele é } \\
\text { menor } \\
\text { comparado a } \\
\text { regiões e países } \\
\text { desenvolvidos }\end{array}$ \\
\hline
\end{tabular}




\begin{tabular}{|c|c|c|c|c|c|c|}
\hline $\begin{array}{l}\text { E5/Arábia } \\
\text { Saudita }\end{array}$ & $\begin{array}{l}\text { Al Gharsan } \\
\text { M, Alarfaj } \\
\text { I/2019 }\end{array}$ & $\begin{array}{l}\text { Avaliar os } \\
\text { conheciment } \\
\text { os e práticas } \\
\text { dos } \\
\text { professores } \\
\text { do ensino } \\
\text { médio em PS }\end{array}$ & $\begin{array}{l}\text { Estudo transversal com } 250 \text { professores } \\
\text { do ensino médio com aplicação de } \\
\text { questionário auto-administrado com } \\
\text { questões sociodemográficas } \\
\text { relacionadas a medidas de PS para } \\
\text { gerenciamento de estudantes com } \\
\text { doenças crônicas e casos de } \\
\text { emergência e práticas anteriores dos } \\
\text { professores em relação a PS }\end{array}$ & 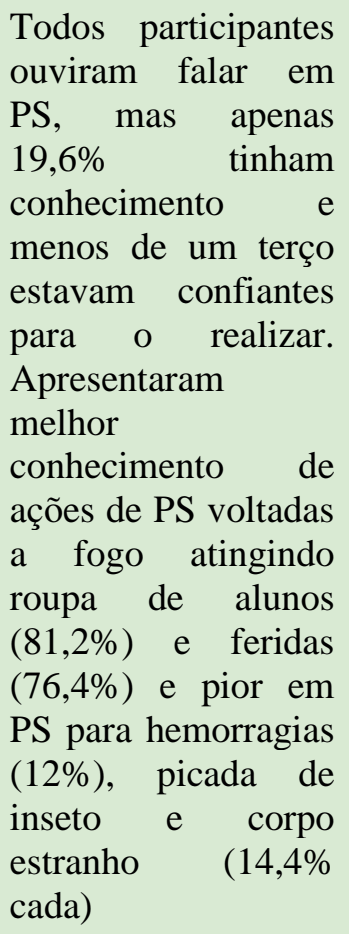 & $\begin{array}{l}\text { Meios de } \\
\text { comunicação em } \\
\text { massa }(60,4 \%), \\
\text { médicos }(13,6 \%) \text { e } \\
\text { livros escolares } \\
\text { educacionais } \\
(7,6 \%)\end{array}$ & $\begin{array}{lr}\text { Os professores } \\
\text { do ensino médio } \\
\text { estão cientes e já } \\
\text { ouviram falar } \\
\text { dos PS, porém } \\
\text { apenas } \\
\text { quinto um } \\
\text { professores } \\
\text { conhecem bem. } \\
\text { A maioria não é } \\
\text { treinada em PS e } \\
\text { apenas } 32 \% \\
\text { estavam } \\
\text { confiantes na sua } \\
\text { realização }\end{array}$ \\
\hline $\begin{array}{l}\text { E6/Arábia } \\
\text { Saudita }\end{array}$ & $\begin{array}{l}\text { AlYahya } \\
\text { IA, } \\
\text { Almohsen } \\
\text { HA, } \\
\text { AlSaleem } \\
\text { IA, Al- } \\
\text { Hamid } \\
\text { MM, } \\
\text { Arafah AM, }\end{array}$ & $\begin{array}{l}\text { Avaliar os } \\
\text { níveis de } \\
\text { conheciment } \\
\text { o de PS entre } \\
\text { professores e } \\
\text { instrutores } \\
\text { das escolas } \\
\text { localizadas } \\
\text { em Riyadh, }\end{array}$ & $\begin{array}{l}\text { Estudo transversal realizado com } 436 \\
\text { professores e instrutores de escola. O } \\
\text { conhecimento de PS foi avaliado por } \\
\text { um questionário }\end{array}$ & $\begin{array}{l}60,1 \% \text { dos } \\
\text { participantes } \\
\text { possuem } \\
\text { informações sobre } \\
\text { PS, enquanto } 39,9 \% \\
\text { não possuem. } \\
\text { Apenas 14,9\% dos } \\
\text { professores } \\
\text { possuíam um bom }\end{array}$ & $\begin{array}{lr}\text { Internet e mídias } \\
\text { sociais } \\
\text { pessoal da saúde } \\
(17 \%), \quad \text { literatura } \\
(14,2 \%), & \text { amigos e } \\
\text { parentes } & (8,9 \%) \text { e } \\
\text { outras } & \text { fontes } \\
(38,3 \%) & \end{array}$ & $\begin{array}{l}\text { A maioria dos } \\
\text { professores } \\
\text { mostra pouco } \\
\text { conhecimento } \\
\text { em PS e resposta } \\
\text { inadequada a } \\
\text { cenários comuns } \\
\text { de emergência }\end{array}$ \\
\hline
\end{tabular}




$\begin{array}{lrl}\text { Al } & \text { Turki } & \text { capital } \\ \text { YA, } & \text { et } & \text { Arábia } \\ \text { al/2019 } & & \text { Saudita }\end{array}$

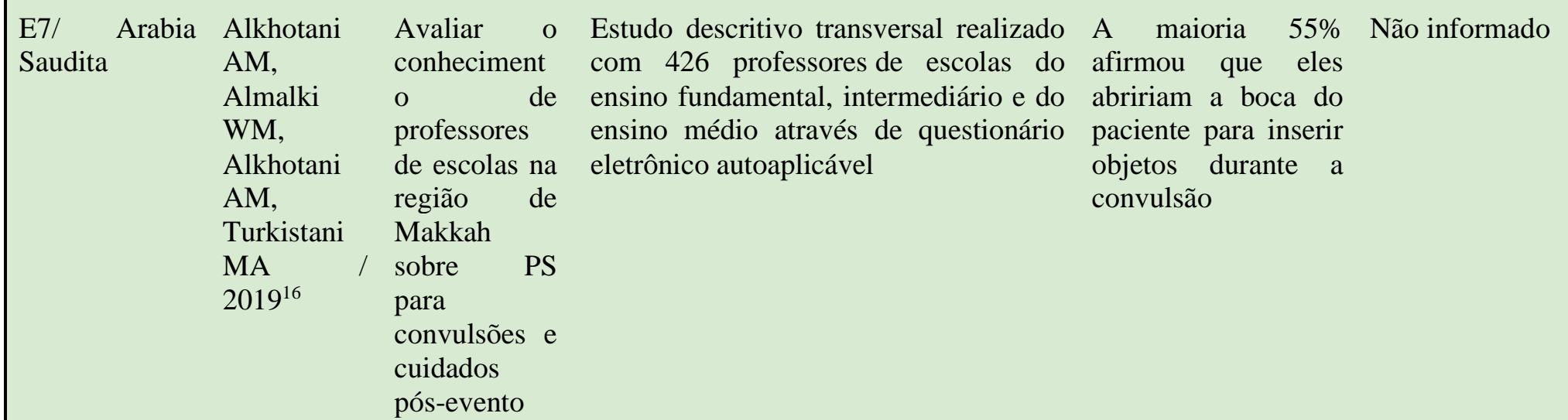

E8/ Arábia Alluqmani Avaliar o Estudo transversal observacional A maioria tinha Não informado. Saudita FA, Omar conheciment realizado com 178 professores por meio pouco conhecimento OM l o dos da aplicação de questionário sobre a gestão de $2018^{17}$ professores estruturado auto administrado que lesões dentárias do ensino abordava informações demográficas traumáticas e poucos fundamental básicas e perguntas sobre o tratamento tinham um e médio de lesões traumáticas dentárias conhecimento aceitá sobre o vel. $28,1 \%$ tinha manejo de conhecimento de PS, lesões mas $93,8 \%$ não obtiveram

traumáticas na cidade de $\quad \mathrm{Al}-$

conhecimento sobre como lidar com lesões dentárias

Os professores da região de Makkah carecem significativamen te

treinamento conhecimento de PS adequados para convulsões 


\begin{tabular}{|c|c|c|c|c|c|c|}
\hline & & $\begin{array}{l}\text { Madinah, } \\
\text { Arábia } \\
\text { Saudita }\end{array}$ & & & & \\
\hline $\begin{array}{l}\text { E9/Emirados } \\
\text { Árabes }\end{array}$ & $\begin{array}{l}\text { Awad MA, } \\
\text { AlHammad } \\
\text { i E, Malalla } \\
\text { M, Maklai } \\
\text { Z, Tariq A, } \\
\text { Al-Ali B, et } \\
\text { al/2017 } 18\end{array}$ & $\begin{array}{l}\text { Avaliar o } \\
\text { nível de } \\
\text { conheciment } \\
\text { o e atitudes } \\
\text { de } \\
\text { professores } \\
\text { do ensino } \\
\text { fundamental } \\
\text { em Dubai e } \\
\text { Sharjah, em } \\
\text { relação a } \\
\text { lesões } \\
\text { dentárias } \\
\text { traumáticas e } \\
\text { m crianças } \\
\text { em idade } \\
\text { escolar }\end{array}$ & $\begin{array}{l}\text { Estudo transversal por meio de } \\
\text { aplicação de um questionário } \\
\text { autoaplicável realizado com } 292 \\
\text { professores do ensino fundamental }\end{array}$ & $\begin{array}{l}43 \% \text { não sabiam o } \\
\text { que fazer em caso de } \\
\text { dente avulsionado e } \\
\text { apenas } 33 \% \text { sabia a } \\
\text { ação correta. } \\
\text { Aproximadamente } \\
37 \% \text { poderiam } \\
\text { fornecer ações } \\
\text { adequadas em caso } \\
\text { de lesões dentárias } \\
\text { traumáticas }\end{array}$ & Não informado & $\begin{array}{l}\text { É necessário } \\
\text { educação sobre } \\
\text { lesões dentárias } \\
\text { traumáticas entre } \\
\text { professores. Um } \\
\text { terço deles não } \\
\text { achavam que } \\
\text { lidar com essa } \\
\text { situação era sua } \\
\text { responsabilidade }\end{array}$ \\
\hline E10/Índia & $\begin{array}{l}\text { Taranath M } \\
\text { Senaikarasi } \\
\text { RM, } \\
\text { Manchanda } \\
\text { K/2017 }\end{array}$ & $\begin{array}{l}\text { Avaliar o } \\
\text { conheciment } \\
\text { o e a atitude } \\
\text { de } \\
\text { professores } \\
\text { de ensino } \\
\text { fundamental } \\
\text { em relação } \\
\text { ao }\end{array}$ & $\begin{array}{l}\text { Estudo realizado por } 3 \text { meses com } 214 \\
\text { professores de } 24 \text { escolas primárias do } \\
\text { governo. Foi aplicado um questionário } \\
\text { no } 1^{\circ} \text { mês. Posteriormente, foi } \\
\text { preparada uma ferramenta educacional } \\
\text { em saúde. } 3^{\circ} \text { mês uso o mesmo } \\
\text { questionário para a avaliação final }\end{array}$ & $\begin{array}{l}\text { Existe falta de } \\
\text { conhecimento entre } \\
\text { os professores sobre } \\
\text { manuseio, transporte } \\
\text { e armazenamento de } \\
\text { um dente } \\
\text { avulsionado. } 70,83 \% \\
\text { tinham o } \\
\text { conhecimento de PS }\end{array}$ & Não informado & $\begin{array}{l}\text { Os professores } \\
\text { do distrito } \\
\text { de East } \\
\text { Panchayat } \\
\text { Madurai têm } \\
\text { pouco } \\
\text { conhecimento } \\
\text { sobre o } \\
\text { tratamento }\end{array}$ \\
\hline
\end{tabular}




\begin{tabular}{|c|c|c|c|c|c|}
\hline & & $\begin{array}{l}\text { gerenciament } \\
\text { o } \\
\text { emergencial } \\
\text { de } \\
\text { traumatismo } \\
\text { dentário e } \\
\text { avulsão } \\
\text { dentária e } \\
\text { testar a } \\
\text { eficácia de } \\
\text { ferramenta } \\
\text { de educação } \\
\text { em saúde }\end{array}$ & & $\begin{array}{l}\text { muito bom após a } \\
\text { ferramenta de } \\
\text { educação, que } \\
\text { inicialmente era } \\
\text { nula. Houve também } \\
\text { aumento na atitude } \\
\text { de professores frente } \\
\text { PS }\end{array}$ & $\begin{array}{l}\text { emergencial de } \\
\text { dentes avulsos }\end{array}$ \\
\hline E11/Índia & $\begin{array}{l}\text { Hosapatna } \\
\text { M, Bhat N, } \\
\text { Prakash J, } \\
\text { Sumalatha } \\
\text { S, } \\
\text { Ankolekar } \\
\text { VH/ } 2020^{20}\end{array}$ & $\begin{array}{l}\text { Avaliar o } \\
\text { nível de } \\
\text { conheciment } \\
\text { o de PS entre } \\
\text { professores } \\
\text { do ensino } \\
\text { fundamental } \\
\text { e avaliar a } \\
\text { eficácia do } \\
\text { treinamento } \\
\text { em PS entre } \\
\text { os socorristas } \\
\text { da escola }\end{array}$ & $\begin{array}{l}\text { Participaram } 150 \text { professores de nove } \\
\text { escolas primárias. Aplicou-se um pré- } \\
\text { teste, posteriormente foi ministrada } \\
\text { palestra sobre PS, logo após os } \\
\text { participantes foram divididos em } 3 \\
\text { grupos com instrutores e aprofundaram } \\
\text { sobre o conhecimento em PS e após o } \\
\text { treinamento realizaram um pós-teste }\end{array}$ & 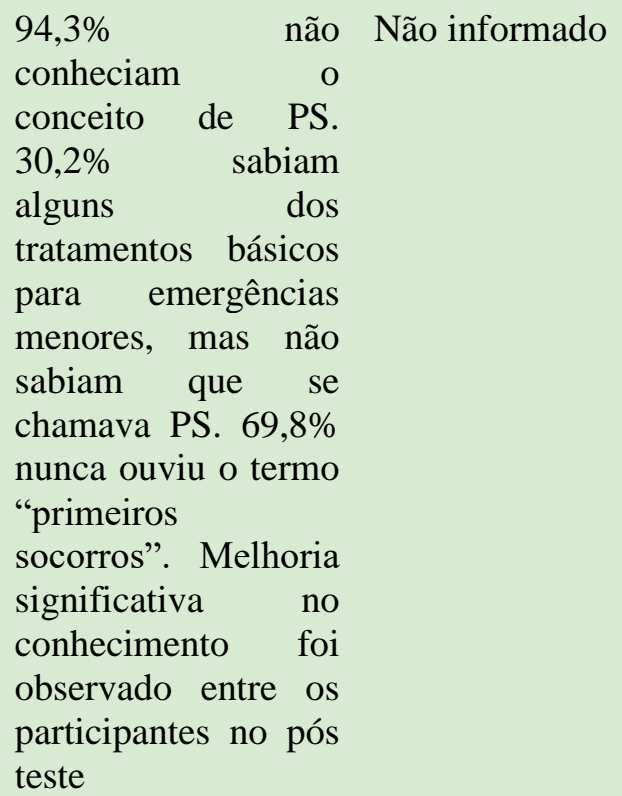 & $\begin{array}{l}\text { O nível de } \\
\text { aptidão no corpo } \\
\text { docente em } \\
\text { Udupi para } \\
\text { supervisionar PS } \\
\text { é insuficiente. A } \\
\text { maioria dos } \\
\text { professores tinha } \\
\text { pouco } \\
\text { conhecimento } \\
\text { sobre } \\
\text { gerenciamento } \\
\text { de PS, mas } \\
\text { apresentaram } \\
\text { interesse no } \\
\text { tema }\end{array}$ \\
\hline
\end{tabular}




\begin{tabular}{|c|c|c|c|c|c|c|}
\hline E12/Irã & $\begin{array}{l}\text { Karimi N, } \\
\text { Heidari } \\
\mathrm{M} / 2015^{21}\end{array}$ & $\begin{array}{l}\text { Avaliar o } \\
\text { conheciment } \\
\text { o a atitude } \\
\text { dos } \\
\text { professores } \\
\text { em relação à } \\
\text { epilepsia, a } \\
\text { fim de } \\
\text { identificar as } \\
\text { necessidades } \\
\text { e exigências } \\
\text { dos alunos } \\
\text { com } \\
\text { epilepsia nas } \\
\text { escolas }\end{array}$ & 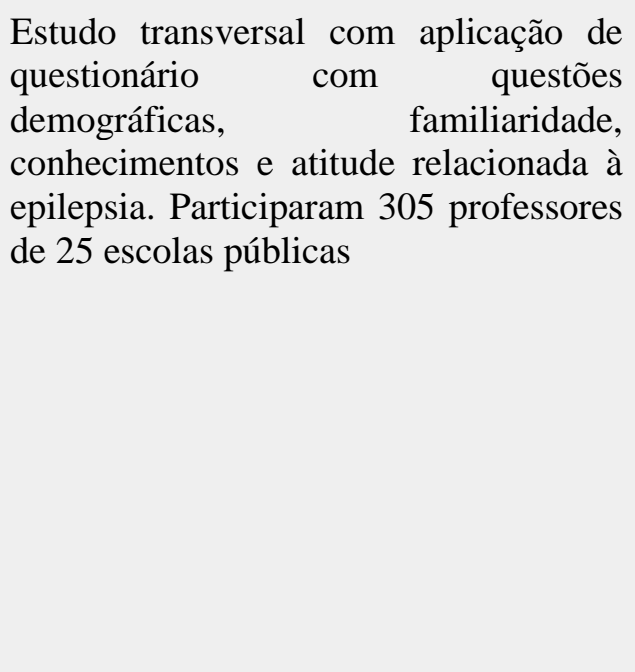 & $\begin{array}{l}97 \% \text { dos } \\
\text { participantes já } \\
\text { ouviram falar sobre } \\
\text { epilepsia. 61,3\% já } \\
\text { observaram um } \\
\text { ataque epilético, mas } \\
\text { somente } 40 \% \\
\text { explicaram sobre PS } \\
\text { nas crises. 82\% } \\
\text { conhecem sintomas } \\
\text { de convulsão. A } \\
\text { maioria não estava } \\
\text { familiarizada com a } \\
\text { gestão de PS em } \\
\text { ataques convulsivos }\end{array}$ & Não informado. & $\begin{array}{l}\text { Este } r \text { estudo } \\
\text { mostrou um bom } \\
\text { conhecimento } \\
\text { geral e atitudes } \\
\text { positivas } \\
\text { relação em } \\
\text { epilepsia entre } \\
\text { os professores } \\
\text { da escola. } \\
\text { Embora } \\
\text { houvesse déficit } \\
\text { em alguns dos } \\
\text { itens e nos PS na } \\
\text { gestão das crises }\end{array}$ \\
\hline E13 /Irã & $\begin{array}{l}\text { Attarzadeh } \\
\text { H, Kebriaei } \\
\text { F, Sadri L, } \\
\text { Foroughi E, } \\
\text { Taghian } \\
\text { Ml/ } 2017^{22}\end{array}$ & $\begin{array}{l}\text { Avaliar o } \\
\text { nível } \\
\text { de conhecim } \\
\text { ento e as } \\
\text { atitudes de } \\
\text { professores } \\
\text { do ensino } \\
\text { fundamental } \\
\text { em relação } \\
\text { ao trauma } \\
\text { dentário e } \\
\text { seu manejo } \\
\text { em Yazd, Irã }\end{array}$ & $\begin{array}{l}\text { Estudo descritivo transversal, realizado } \\
\text { com } 281 \text { professores do ensino } \\
\text { fundamental por meio de aplicação de } \\
\text { questionário }\end{array}$ & $\begin{array}{l}\text { A pontuação total de } \\
\text { conhecimento dos } \\
\text { professores sobre o } \\
\text { manejo de traumas } \\
\text { dentais foi } \\
\text { relativamente baixa. } \\
\text { Mais de 94\% dos } \\
\text { participantes } \\
\text { achavam que seu } \\
\text { conhecimento era } \\
\text { insuficiente }\end{array}$ & Não informado & $\begin{array}{l}\text { O conhecimento } \\
\text { atual dos } \\
\text { professores } \\
\text { sobre PS em } \\
\text { emergências } \\
\text { odontológicas é } \\
\text { baixo e sua } \\
\text { atitude frente a } \\
\text { essas situações é } \\
\text { relativamente } \\
\text { normal }\end{array}$ \\
\hline
\end{tabular}


Kolahi AA, Determinar

- Valukolaei os, atitudes e

M, Abbasi- medidas de

Kangevari PS sobre

M, Farsar epilepsia

$\mathrm{AR} / 2018^{23}$ entre

professores

do ensino

fundamental

em duas

cidades da

província de

Mazandaran,

no norte do

Irã
Ghorbanpur conheciment
Estudo transversal realizado com 323 Nível

\section{professores. Foi aplicado um conhecimento}

questionário estruturado com questões

sobre conhecimentos gerais, causas,

sintomas, desencadeadores de crises,

medidas de PS e tratamento

recomendados para epilepsia. A escal

de Likert foi utilizada para a seção de atitudes

e

muito alto foi

$43 \%$ alto, $44 \%$

moderado e $5 \%$

baixo, o que

insuficiente. Apenas

$3 \%$ se sentiam

suficientemente

informados

epilepsia.

pontuação

medidas de PS

$7 \%$ foi muito alta

$71 \%$ alta e $22 \%$

baixa, o que é

considerado

útil. Mais de 91\%

conheciam pelo

menos três medidas

corretas de PS
Meios audiovisuais $\mathrm{O}$ conhecimento (29,7\%); mídia dos professores impressa (22,3\%); sobre epilepsia familiares e era insuficiente, parentes $(15,4 \%)$; porém

as profissionais de atitudes eram saúde $\quad(10,5 \%)$; geralmente amigos (10,5\%); positivas e as colegas (6,9\%); medidas de PS panfletos e na convulsão pôsteres $(4,0 \%)$; foram bastante
A 5 professores úteis

tinham como fonte a Internet

\%

\begin{tabular}{|c|c|c|c|c|c|c|}
\hline E15/ Irã & $\begin{array}{l}\text { Adib- } \\
\text { Hajbaghery } \\
\text { M, } \\
\text { Kamrava } \\
\text { Z/2019 }\end{array}$ & $\begin{array}{l}\text { Avaliar o } \\
\text { conheciment } \\
\text { o dos } \\
\text { professores } \\
\text { de ensino } \\
\text { fundamental } \\
\text { e } \\
\text { médio sobre }\end{array}$ & $\begin{array}{l}\text { Estudo transversal. Foi aplicado um } \\
\text { questionário com itens sobre questões } \\
\text { sociodemográficas e práticas básicas de } \\
\text { PS. População: } 196 \text { professores de } \\
\text { escolas públicas e particulares de } \\
\text { ensino fundamental e médio na cidade } \\
\text { de Kashan, no Irã }\end{array}$ & $\begin{array}{l}59,7 \% \text { dos } \\
\text { professores } \\
\text { avaliaram seus } \\
\text { conhecimentos } \\
\text { como moderados e } \\
8,2 \% \text { como bons. } \\
\text { Ninguém possuía } \\
\text { bons conhecimentos }\end{array}$ & $\begin{array}{l}\text { Livros }(33,3 \%), \\
\text { internet }(33,3 \%) \text { e } \\
\text { mídia }(21,2 \%)\end{array}$ & $\begin{array}{lr}\text { A maioria } & \text { dos } \\
\text { professores } & \text { não } \\
\text { possuía } & \\
\text { conhecimento } \\
\text { suficiente sobre } \\
\text { os PS. } \quad \mathrm{Na} \\
\text { maioria } & \text { das } \\
\text { vezes, eles } & \text { não }\end{array}$ \\
\hline
\end{tabular}




\begin{tabular}{|c|c|c|c|c|c|c|}
\hline & & $\begin{array}{l}\text { os PS em } \\
\text { Kashan, Irã }\end{array}$ & & $\begin{array}{l}\text { de PS, mas } 63,3 \% \\
\text { tinha conhecimento } \\
\text { moderado e } 36,7 \% \\
\text { fraco. } \\
\text { conhecimento fo } \\
\text { maior entre os que já } \\
\text { tiveram experiências } \\
\text { com situações que } \\
\text { requerem PS na } \\
\text { escola comparado } \\
\text { com os que não } \\
\text { tiveram }\end{array}$ & & $\begin{array}{l}\text { receberam } \\
\text { treinamento em } \\
\text { PS. Ações } \\
\text { urgentes } \\
\text { parecem } \\
\text { necessárias para } \\
\text { a formação de } \\
\text { professores em } \\
\text { PS }\end{array}$ \\
\hline E16/ Líbano & $\begin{array}{l}\text { Abou } \\
\text { Khaled KJ, } \\
\text { Ibrahim MI, } \\
\text { Moussa RF } \\
/ 2020^{25}\end{array}$ & $\begin{array}{l}\text { Avaliar o } \\
\text { impacto } \\
\text { direto de um } \\
\text { curso de } \\
\text { formação } \\
\text { sobre } \\
\text { epilepsia em } \\
\text { escolas } \\
\text { públicas e } \\
\text { privadas no } \\
\text { Líbano por } \\
\text { meio de um } \\
\text { questionário } \\
\text { específico } \\
\text { sobre a } \\
\text { atitude e o } \\
\text { conheciment } \\
\text { o de } \\
\text { professores }\end{array}$ & $\begin{array}{l}\text { Foi aplicado com } 73 \text { professores um } \\
\text { pré teste por um questionário para } \\
\text { avaliar o conhecimentos dos } \\
\text { professores antes do treinamento sobre } \\
\text { epilepsia e um pós teste para avaliar os } \\
\text { conhecimentos após o treinamento }\end{array}$ & 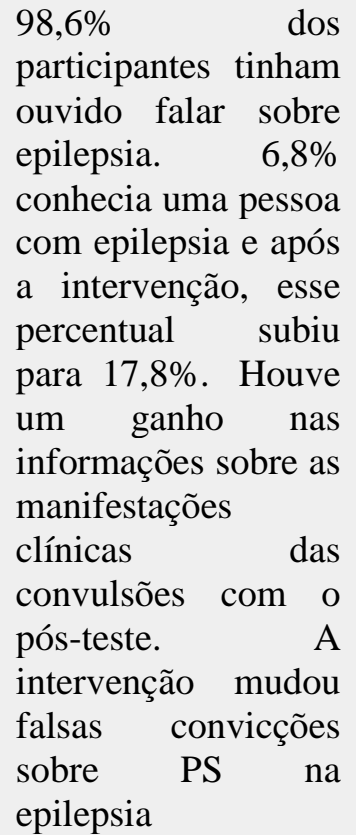 & Não informado & $\begin{array}{l}\text { Os professores e } \\
\text { conselheiros } \\
\text { estavam } \\
\text { familiarizados } \\
\text { com a epilepsia, } \\
\text { porém tinham } \\
\text { lacunas } \\
\text { conceitos } \\
\text { errôneos no } \\
\text { conhecimento } \\
\text { especialmente } \\
\text { sobre PS e } \\
\text { tratamento da } \\
\text { convulsão. } \mathrm{O} \\
\text { treinamento } \\
\text { demonstrou um } \\
\text { resultado } \\
\text { positivo }\end{array}$ \\
\hline
\end{tabular}




\begin{tabular}{|c|c|c|c|c|c|c|}
\hline & & $\begin{array}{l}\text { antes e } \\
\text { depois da } \\
\text { intervenção }\end{array}$ & & & & \\
\hline E17/Paquistão & $\begin{array}{l}\text { Qureshi } \\
\text { FM, Khalid } \\
\text { N, Nigah-e- } \\
\text { mumtaz S, } \\
\text { Assad T, } \\
\text { Noreen } \\
\text { K/2018 }\end{array}$ & $\begin{array}{l}\text { Avaliar a } \\
\text { disponibilida } \\
\text { de de } \\
\text { instalações } \\
\text { de PS dentro } \\
\text { das escolas } \\
\text { da cidade de } \\
\text { Karachi, bem } \\
\text { como } \\
\text { avaliação de } \\
\text { professores } \\
\text { na sua } \\
\text { formação em } \\
\text { PS }\end{array}$ & $\begin{array}{l}\text { Estudo transversal realizado com } 209 \\
\text { professores de escolas de ensino } \\
\text { fundamental e médio por meio de um } \\
\text { questionário } \\
\text { individualmente através de uma } \\
\text { entrevista oral }\end{array}$ & $\begin{array}{l}31,57 \% \text { dos } \\
\text { professores } \\
\text { possuíam } \\
\text { conhecimento em } \\
\text { emergências } \\
\text { médicas. 56\% estava } \\
\text { disposta a fazer o } \\
\text { curso de } \\
\text { gerenciamento de PS } \\
\text { e 91,38\% } \\
\text { considerou-o } \\
\text { essencial para a vida } \\
\text { profissional }\end{array}$ & Não informado & $\begin{array}{lr}\text { Há deficiências } \\
\text { em instalações } \\
\text { de PS em várias } \\
\text { escolas } \\
\text { Karachi, bem } \\
\text { como } \\
\text { professores } \\
\text { treinados em } \\
\text { relação aos PS }\end{array}$ \\
\hline E18/ Turquia & $\begin{array}{l}\text { Faydali S, } \\
\text { Küçük S, } \\
\text { Yeşilyurt } \\
\text { M/2018 }\end{array}$ & $\begin{array}{l}\text { Identificar } \\
\text { situações em } \\
\text { que os } \\
\text { professores, } \\
\text { frequenteme } \\
\text { nte, } \\
\text { encontram a } \\
\text { necessidade } \\
\text { de } \\
\text { administrar } \\
\text { PS às }\end{array}$ & $\begin{array}{l}\text { Estudo descritivo com } 331 \text { professores } \\
\text { que trabalhavam em escolas primárias e } \\
\text { secundárias. Foi realizada aplicação de } \\
\text { questionários por meio de entrevista } \\
\text { presencial }\end{array}$ & $\begin{array}{lr}\text { Apenas } 32,3 \% & \text { dos } \\
\text { professores } & \\
\text { afirmaram poder } & \text { prestar PS nas } \\
\text { situações de acidente } \\
\text { e lesão. } \\
\text { acharam } \\
\text { possuíam } \\
\text { conhecimento } \\
\text { adequado em PS }\end{array}$ & Não informado & $\begin{array}{lr}\text { O treinamento é } \\
\text { realizado nas } \\
\text { escolas e } & \text { há } \\
\text { informações } & \\
\text { sobre } & \text { as } \\
\text { situações que } & \text { requerem PS, } \\
\text { mas os docentes } \\
\text { são incapazes de } \\
\text { transferir esse } \\
\text { aprendizado para }\end{array}$ \\
\hline
\end{tabular}




\begin{tabular}{|c|c|c|c|c|c|c|}
\hline & & $\begin{array}{l}\text { crianças e se } \\
\text { os } \\
\text { professores } \\
\text { executaram a } \\
\text { aplicação } \\
\text { correta } \\
\text { nesses } \\
\text { eventos }\end{array}$ & & & & a prática \\
\hline E19/Etiópia & $\begin{array}{l}\text { Gebrewold } \\
\text { MA, } \\
\text { Enquselassi } \\
\text { e r F, } \\
\text { Teklehaima } \\
\text { not R, } \\
\text { Gugssa } \\
/ 2016^{28}\end{array}$ & $\begin{array}{l}\text { Avaliar e } \\
\text { entender os } \\
\text { determinante } \\
\mathrm{s} \text { sociais e } \\
\text { demográficos } \\
\text { do } \\
\text { conheciment } \\
\text { o, atitude e } \\
\text { prática dos } \\
\text { professores } \\
\text { em relação a } \\
\text { pessoas com } \\
\text { epilepsia em } \\
\text { Adis Abeba, } \\
\text { Etiópia }\end{array}$ & $\begin{array}{l}\text { Estudo realizado com } 844 \text { professores } \\
\text { do ensino fundamental e médio de } \\
\text { escolas públicas e privadas por meio de } \\
\text { questionário autoaplicado com questões } \\
\text { sociodemográficas e identificação } \\
\text { geral com dados sobre conhecimento, } \\
\text { atitude e prática relacionada à epilepsia }\end{array}$ & $\begin{array}{l}90 \% \text { conheciam a } \\
\text { epilepsia como } \\
\text { doença. Proteger } \\
\text { contra lesões, limpar } \\
\text { as vias aéreas, } \\
\text { chamar médicos e } \\
\text { distanciar alunos } \\
\text { foram destacadas } \\
\text { como ações de PS. } \\
\text { Surgiram outras } \\
\text { culturalmente } \\
\text { plausíveis como } \\
\text { cheirar fumaça de } \\
\text { fósforo, derramar } \\
\text { água no rosto, inserir } \\
\text { uma mordaça na } \\
\text { boca }\end{array}$ & $\begin{array}{l}\text { Familiaridade com } \\
\text { pessoas com } \\
\text { epilepsia }(51,3 \%) \text {, } \\
\text { mídia }(36,9 \%) \text { e } \\
\text { médicos }(2,3 \%)\end{array}$ & $\begin{array}{l}\text { Os professores } \\
\text { tinham } \\
\text { consciência, } \\
\text { conhecimento, } \\
\text { atitudes e } \\
\text { práticas em } \\
\text { relação a pessoas } \\
\text { com epilepsia } \\
\text { comparado com } \\
\text { outros estudos } \\
\text { de países pobres } \\
\text { em recursos }\end{array}$ \\
\hline
\end{tabular}




\begin{tabular}{|c|c|c|c|c|c|c|c|}
\hline E20/Etiópia & $\begin{array}{l}\text { Berhe } \\
\text { Yihun } \\
\text { Abebe } \\
\text { Abera } \\
\mathrm{H} / 2017^{29}\end{array}$ & $\begin{array}{l}\mathrm{T}, \\
\mathrm{B},\end{array}$ & $\begin{array}{l}\text { Descobrir o } \\
\text { conheciment } \\
\text { o, atitude e } \\
\text { prática em } \\
\text { relação à } \\
\text { epilepsia } \\
\text { entre os } \\
\text { professores } \\
\text { de } \\
\text { uma escola }\end{array}$ & \begin{tabular}{lcr}
\multicolumn{2}{l}{ Estudo transversal realizado com } & 135 \\
professores & por $\quad$ meio de & um \\
questionário & semiestruturado & e \\
autoaplicável & &
\end{tabular} & \begin{tabular}{lr} 
Apenas & \multicolumn{2}{r}{ nunca } \\
ouviram & falar de \\
epilepsia. & $53,5 \%$ \\
dos entrevistados \\
possuíam & bons \\
conhecimentos & de \\
epilepsia e & $15,7 \%$ \\
possuíam & pouco \\
conhecimento & da \\
doença &
\end{tabular} & $\begin{array}{lr}\text { Pais e } & \text { amigos } \\
44,9 \% ; & \text { Mídia } \\
\text { eletrônica } & 34,6 \% \text {; } \\
\text { Profissional } & \text { de } \\
\text { saúde } & 34,6 \% \text {; } \\
\text { Livros } & 8,7 \% \text {; } \\
\text { Internet } & 3,1 \%\end{array}$ & $\begin{array}{l}\text { Uma proporção } \\
\text { significativa de } \\
\text { professores } \\
\text { apresentou } \\
\text { déficits } \\
\text { termos em } \\
\text { conhecimento } \\
\text { geral, atitude e } \\
\text { manejo } \\
\text { adequado da } \\
\text { epilepsia }\end{array}$ \\
\hline E21/ Etiópia & $\begin{array}{l}\text { Ganfure } \\
\text { Ameya } \\
\text { Tamirat } \\
\text { Lencha } \\
\text { Bikila } \\
\text { D/2018 }\end{array}$ & $\begin{array}{l}\mathrm{G}, \\
\mathrm{G}, \\
\mathrm{A}, \\
\mathrm{B},\end{array}$ & $\begin{array}{l}\text { Investigar } \\
\text { conheciment } \\
\text { os, atitudes, } \\
\text { práticas e } \\
\text { fatores } \\
\text { associados de } \\
\text { PS entre } \\
\text { professores } \\
\text { de educação } \\
\text { infantil da } \\
\text { sub-cidade } \\
\text { de Lideta, } \\
\text { Addis } \\
\text { Abeba, } \\
\text { Etiópia }\end{array}$ & $\begin{array}{l}\text { Estudo transversal. Os dados foram } \\
\text { coletados usando questionário pré- } \\
\text { testado, estruturado e autoaplicável } \\
\text { realizado com } 194 \text { participantes }\end{array}$ & $\begin{array}{l}40,2 \% \text { dos } \\
\text { entrevistados } \\
\text { pontuaram acima da } \\
\text { média para } \\
\text { conhecimento em } \\
\text { PS. Um quarto } \\
\text { conhece a } \\
\text { importância dos } \\
\text { PS para dificuldades } \\
\text { respiratórias, } \\
\text { fraturas e lesões no } \\
\text { pescoço e nas costas }\end{array}$ & $\begin{array}{l}53,1 \%, 22,2 \% \text { e } \\
14,4 \% \text { ouviram } \\
\text { falar de PS por } \\
\text { profissionais de } \\
\text { saúde, mídia e } \\
\text { instituição de } \\
\text { saúde, } \\
\text { respectivamente, } \\
\text { enquanto o restante } \\
\text { ouviu outras } \\
\text { fontes, como } \\
\text { família e livros }\end{array}$ & $\begin{array}{l}\text { O conhecimento } \\
\text { dos professores } \\
\text { em relação aos } \\
\text { PS é baixo. A } \\
\text { maioria, } \\
\text { expostos a } \\
\text { crianças com } \\
\text { necessidade de } \\
\text { PS, não estavam } \\
\text { com as práticas } \\
\text { de PS } \\
\text { adequadas }\end{array}$ \\
\hline
\end{tabular}




\begin{tabular}{|c|c|c|c|c|c|c|}
\hline E22/Nigéria & $\begin{array}{l}\text { Eze CN, } \\
\text { Ebuehi } \\
\text { OM, Brigo } \\
\text { F, Otte } \\
\text { WM, Igwe } \\
\text { SC/2015 }\end{array}$ & 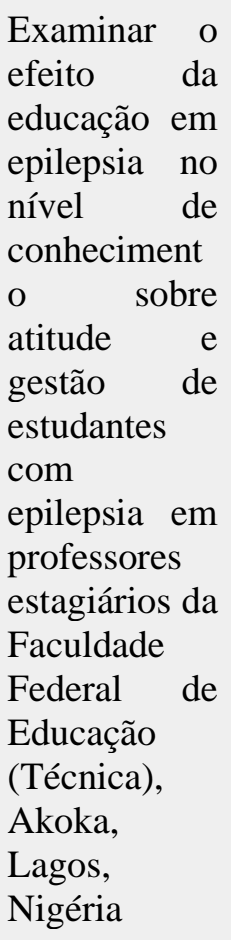 & $\begin{array}{l}\text { Realizado com } 226 \text { professores } \\
\text { estagiários por meio de questionário } \\
\text { auto-administrado a fim de avaliar } \\
\text { conhecimento, atitudes e gestão de PS } \\
\text { em epilepsia aplicado antes e após } \\
\text { intervenção que consistiu em uma } \\
\text { palestra com duração de uma hora e } \\
\text { meia }\end{array}$ & $\begin{array}{l}\text { A maioria ouviu ou } \\
\text { leu sobre epilepsia. } \\
\text { Houve diferenças } \\
\text { significativas nos } \\
\text { escores de } \\
\text { conhecimento pós- } \\
\text { intervenção. Antes } \\
\text { da intervenção, } \\
32,9 \% \text { sabiam o que } \\
\text { fazer se uma criança } \\
\text { tivesse um ataque } \\
\text { epiléptico, após a } \\
\text { intervenção esse } \\
\text { número subiu para } \\
49,5 \% \text { and }\end{array}$ & $\begin{array}{l}\text { TV / rádio / jornal / } \\
\text { revista } \quad(44,7 \%), \\
\text { livros } \quad(42,5 \%), \\
\text { médicos/enfermeir } \\
\text { os } \quad(40,7 \%), \\
\text { parentes }(28,8 \%) \text { e } \\
\text { internet }(14,2 \%)\end{array}$ & $\begin{array}{l}\text { Notou-se um } \\
\text { conhecimento } \\
\text { deficiente, } \\
\text { atitudes } \\
\text { negativas e } \\
\text { habilidades } \\
\text { precárias de PS } \\
\text { dos professores } \\
\text { estagiários. } \\
\text { Houve uma } \\
\text { melhora } \\
\text { significativa no } \\
\text { conhecimento, } \\
\text { atitudes } \\
\text { habilidades }\end{array}$ \\
\hline E23/Sudão & $\begin{array}{l}\text { Elhassan } \\
\text { MA, } \\
\text { Alemairy } \\
\text { AA, Amara } \\
\text { ZM, } \\
\text { Hamadelne } \\
\text { el AA, } \\
\text { Mohamed } \\
\text { AH, }\end{array}$ & $\begin{array}{l}\text { Avaliar o } \\
\text { conheciment } \\
\text { o, atitude e } \\
\text { prática de } \\
\text { professores } \\
\text { do ensino } \\
\text { médio em } \\
\text { relação a } \\
\text { epilepsia no }\end{array}$ & $\begin{array}{l}\text { Estudo transversal realizado com } 317 \\
\text { professores do ensino médio por meio } \\
\text { de questionários autoaplicáveis }\end{array}$ & $\begin{array}{lr}\text { A maioria } & \text { dos } \\
\text { professores } & \text { sabiam } \\
\text { sobre o } & \text { termo } \\
\text { epilepsia. } & \mathrm{A} \\
\text { pontuação } & \text { média } \\
\text { geral } & \text { do } \\
\text { conhecimento } & \text { foi } \\
\text { considerada } & \text { como } \\
\text { intermediário. } & \end{array}$ & Não informado & $\begin{array}{l}\text { Existe um alto } \\
\text { nível de } \text { atitude } \\
\text { negativa } \\
\text { relação } \\
\text { pacientes } \\
\text { epiléticos. Tem- } \\
\text { se bom nível de } \\
\text { prática positiva } \\
\text { quanto às crises }\end{array}$ \\
\hline
\end{tabular}




\begin{tabular}{|c|c|c|c|c|c|c|}
\hline & $\begin{array}{l}\text { Elaimeri } \\
\text { AA/2017 }\end{array}$ & $\begin{array}{l}\text { estado de } \\
\text { Cartum } \\
\text { Sudão }\end{array}$ & & $\begin{array}{l}\text { Quanto ao escore } \\
\text { médio para a prática } \\
\text { com epilepsia, eles } \\
\text { atingiram um escore } \\
\text { considerado baixo }\end{array}$ & & $\begin{array}{l}\text { epilépticas e } \\
\text { medidas de PS, } \\
\text { mas há também } \\
\text { práticas } \\
\text { negativas }\end{array}$ \\
\hline E24/Brasil & $\begin{array}{l}\text { Antunes } \\
\text { LA, } \\
\text { Rodrigues } \\
\text { AS, Martins } \\
\text { AM, } \\
\text { Cardoso } \\
\text { ES, Homsi } \\
\text { N, Antunes } \\
\text { LS/2015 }\end{array}$ & $\begin{array}{l}\text { Avaliar o } \\
\text { conheciment } \\
\text { o e as ações } \\
\text { de um grupo } \\
\text { de } \\
\text { professores } \\
\text { brasileiros } \\
\text { em relação } \\
\text { ao traumatismo } \\
\text { dentário em } \\
\text { dentes } \\
\text { permanentes }\end{array}$ & $\begin{array}{l}\text { Estudo transversal. Participaram } 205 \\
\text { professores, da } 1^{\mathrm{a}} \text { à } 9^{\mathrm{a}} \text { séries, de } 27 \\
\text { escolas que responderam um } \\
\text { questionário estruturado e autoaplicável }\end{array}$ & $\begin{array}{l}92,1 \% \text { relataram não } \\
\text { ter conhecimento de } \\
\text { trauma dentário e } \\
93,7 \% \text { dos } \\
\text { professores não se } \\
\text { sentiam preparados } \\
\text { para prestar socorro }\end{array}$ & Não informado & $\begin{array}{l}\text { Existe falta de } \\
\text { conhecimento } \\
\text { técnico em parte } \\
\text { dos professores } \\
\text { em relação ao } \\
\text { manejo do } \\
\text { traumatismo } \\
\text { dentário nos } \\
\text { alunos }\end{array}$ \\
\hline E25/ Brasil & $\begin{array}{l}\text { Alves LS, } \\
\text { Freitas VJ, } \\
\text { Rosendo } \\
\text { RA, } \\
\text { Gominho } \\
\text { LF, } \\
\text { Sarmento } \\
\text { TC/ } 2015^{34}\end{array}$ & $\begin{array}{l}\text { Avaliar o } \\
\text { nível de } \\
\text { conheciment } \\
\text { o dos } \\
\text { professores } \\
\text { do ensino } \\
\text { fundamental } \\
\text { da rede } \\
\text { particular de } \\
\text { ensino sobre } \\
\text { o }\end{array}$ & $\begin{array}{l}\text { Estudo transversal do tipo censitário } \\
\text { realizado com } 138 \text { professores por meio } \\
\text { da aplicação de questionário } \\
\text { estruturado acerca da conduta imediata } \\
\text { com criança após traumatismo dental }\end{array}$ & $\begin{array}{l}\text { Notou-se uma falta } \\
\text { de conhecimento dos } \\
\text { professores sobre PS } \\
\text { em casos de } \\
\text { traumatismo } \\
\text { dentário, mostrando } \\
\text { assim r uma } \\
\text { deficiência r de } \\
\text { conhecimento r } \\
\text { científico sobre o } \\
\text { assunto }\end{array}$ & $\begin{array}{l}\text { Atendimento a } \\
\text { vítima de trauma } \\
\text { dental }(43,5 \%) ; \\
\text { Palestra }(21,7 \%) ; \\
\text { Leitura }(26,1 \%) \\
\text { Outros }(8,7 \%)\end{array}$ & $\begin{array}{l}\text { Os professores } \\
\text { demonstram } \\
\text { pouco } \\
\text { conhecimento } \\
\text { sobre PS em } \\
\text { casos de traumas } \\
\text { dentários, } \\
\text { indicando } \\
\text { grande } \\
\text { necessidade de } \\
\text { capacitação e }\end{array}$ \\
\hline
\end{tabular}




atendimento
imediato de
vítimas de
traumatismo
dentário e
ambiente
escolar

E26/Brasil Carmo HO, Investigar as Souza RC, atitudes dos Araújo CL, docentes de Francisco uma escola $\mathrm{AG} / 2017^{35}$ de educação infantil diante de um acidente

escolar abordagem qualitativa, desenvolvido identificaram fatores em uma escola privada, situada no e locais de riscos aos interior do estado de São Paulo, com seus alunos. Seis dez professores de ensino fundamental tiveram na formação I $\left(1^{\circ}\right.$ ao $4^{\circ}$ ano $)$

\section{Avaliar}

o

Calandrim

conheciment

de esco

$\mathrm{AB}$,

o

de

Oliveira

LR,

professores

funcionários

Massaro

acerca de PS

LG,

Vedovato

CL,

Boaventura

$\mathrm{AP} / 2017^{3}$ acesso ao conteúdo de PS e revelaram que a instituição de trabalho não

forneceu preparo em acidentes escolares

\section{parti}

teórico-prático, imediatamente após práticos sobre

$\begin{array}{ll}\text { aplicou-se pós-teste } & \begin{array}{l}\text { identificação e } \\ \text { chamar ajuda teve }\end{array}\end{array}$ acesso

informação
Os educadores demonstram ser leigos em

relação ao atendimento

inicial acidentes

escolares, mas apresentam grande interesse em aprender

O treinamento é efetivo, com aumento significativo da porcentagem de acertos após a realização do curso, com desempenho dos profissionais acima de 90,0\% 


\begin{tabular}{|c|c|c|c|c|c|c|}
\hline & & & & $\begin{array}{l}\text { antes de } 20,0 \% \text { e } \\
\text { após o treinamento } \\
\text { foi para } 89,5 \% \text {. } \\
\text { Após o treinamento } \\
\text { aumentou } \quad \text { a } \\
\text { porcentagem de } \\
\text { acerto em todas as } \\
\text { questões que } \\
\text { avaliaram }\end{array}$ & & $\begin{array}{l}\text { nas avaliações a } \\
\text { habilidade e dos } \\
\text { conhecimentos } \\
\text { em PS no } \\
\text { ambiente escolar }\end{array}$ \\
\hline E28/ Brasil & $\begin{array}{l}\text { Galindo } \\
\text { Neto NM, } \\
\text { Carvalho } \\
\text { GCN, } \\
\text { Castro } \\
\text { RCMB, } \\
\text { Caetano JA, } \\
\text { Santos Silva } \\
\text { ECB, SM et } \\
\text { TM al/2018 }\end{array}$ & $\begin{array}{l}\text { Desvelar } \\
\text { vivências de } \\
\text { professores } \\
\text { do ensino } \\
\text { infantil e } \\
\text { fundamental } \\
\text { sobre PS na } \\
\text { escola à luz } \\
\text { da teoria do } \\
\text { empoderame } \\
\text { nto }\end{array}$ & $\begin{array}{l}\text { Estudo descritivo, exploratório de } \\
\text { abordagem qualitativa. O grupo focal } \\
\text { foi utilizado como fonte de dados. } \\
\text { Realizaram dois encontros com um } \\
\text { grupo de nove professores e para coleta } \\
\text { de dados utilizou-se um roteiro com } \\
\text { questões norteadoras. As falas foram } \\
\text { gravadas e posteriormente transcritas } \\
\text { na íntegra }\end{array}$ & $\begin{array}{l}\text { Algumas condutas } \\
\text { de PS são } \\
\text { conhecidas por eles. } \\
\text { Há consciência do } \\
\text { despreparo quanto } \\
\text { ao PS e reconhecem } \\
\text { a importância de } \\
\text { acionar o serviço } \\
\text { pré-hospitalar } \\
\text { móvel. Possuem } \\
\text { conhecimentos e } \\
\text { habilidades } \\
\text { incipientes para os } \\
\text { PS e demonstravam } \\
\text { medo e insegurança } \\
\text { para comunicar os } \\
\text { familiares }\end{array}$ & $\begin{array}{l}\text { Experiência } \\
\text { materna, por } \\
\text { envolver o cuidado } \\
\text { com os filhos; } \\
\text { Crença alicerçada } \\
\text { em populares }\end{array}$ & $\begin{array}{lr}\text { Os professores } \\
\text { apontaram que } \\
\text { existe uma } \\
\text { lacuna } \\
\text { empoderamento } \\
\text { acerca dos } \\
\text { formação. } \\
\text { Ademais, } \\
\text { destacaram a } \\
\text { necessidade de } \\
\text { se empoderar } \\
\text { para agir nos } \\
\text { agravos } \\
\text { vivenciados }\end{array}$ \\
\hline E29/ Brasil & $\begin{array}{l}\text { Zonta JB, } \\
\text { Eduardo } \\
\text { AHA, }\end{array}$ & $\begin{array}{l}\text { Analisar as } \\
\text { contribuições } \\
\text { da simulação }\end{array}$ & $\begin{array}{l}\text { Estudo quase experimental, do tipo pré } \\
\text { e pós-teste, com } 76 \text { professores por } \\
\text { meio da aplicação de dois instrumentos }\end{array}$ & $\begin{array}{l}\text { O escore médio de } \\
\text { autoconfiança pré } \\
\text { simulação in situ foi }\end{array}$ & Não informado & $\begin{array}{l}\text { Os professores } \\
\text { sentem-se pouco } \\
\text { confiantes para }\end{array}$ \\
\hline
\end{tabular}




\begin{tabular}{|c|c|c|c|c|c|c|}
\hline & $\begin{array}{l}\text { Ferreira } \\
\text { MVF, } \\
\text { Chaves GH, } \\
\text { Okido ACC } \\
12019^{37}\end{array}$ & $\begin{array}{l}\text { in situ na } \\
\text { autoconfianç } \\
\text { a de } \\
\text { professores } \\
\text { da educação } \\
\text { infantil e } \\
\text { fundamental } \\
\text { I com relação } \\
\text { ao manejo } \\
\text { inicial das } \\
\text { intercorrênci } \\
\text { as de saúde } \\
\text { na escola }\end{array}$ & $\begin{array}{l}\text { pré e pós simulação in situ, os quais } \\
\text { foram: escala visual analógica de } \\
\text { autoconfiança dos professores para } \\
\text { manejo das intercorrências de saúde na } \\
\text { escola e questionário }\end{array}$ & $\begin{array}{l}4.13 \text { e após foi } 6.92 \text {. } \\
\text { O item com maior } \\
\text { diferença foi: "eu me } \\
\text { sinto confiante para } \\
\text { oferecer o primeiro } \\
\text { atendimento a uma } \\
\text { criança que está } \\
\text { convulsionando". O } \\
\text { com menor escore } \\
\text { médio foi referente } \\
\text { ao primeiro } \\
\text { atendimento a uma } \\
\text { criança desacordada } \\
\text { e sem respirar }\end{array}$ & & $\begin{array}{l}\text { manejar } \\
\text { intercorrências } \\
\text { de saúde na } \\
\text { escola, contudo, } \\
\text { após simulação } \\
\text { observou-se } \\
\text { promoção da } \\
\text { autoconfiança }\end{array}$ \\
\hline E30/ Brasil & $\begin{array}{l}\text { Brito JG, } \\
\text { Oliveira IP, } \\
\text { Godoy CB, } \\
\text { França AP/ } \\
2020^{2}\end{array}$ & $\begin{array}{l}\text { Analisar o } \\
\text { efeito de uma } \\
\text { capacitação } \\
\text { no } \\
\text { conheciment } \\
\text { o da equipe } \\
\text { multidiscipli } \\
\text { nar de } \\
\text { escolas de } \\
\text { ensino } \\
\text { especializado } \\
\text { sobre PS } \\
\text { diante de } \\
\text { acidentes } \\
\text { escolares. }\end{array}$ & $\begin{array}{l}\text { Estudo quase experimental realizado } \\
\text { em sete escolas de ensino especializado } \\
\text { para crianças, adolescentes e jovens } \\
\text { com deficiência. Foi aplicado } \\
\text { um questionário semiestruturado e } \\
\text { realizadas capacitações, pré-teste e pós- } \\
\text { teste. Participaram } 162 \text { profissionais de } \\
\text { nível superior, sendo destes 82,1\% } \\
\text { docentes. }\end{array}$ & $\begin{array}{l}\text { Houve aumento } \\
\text { significativo no } \\
\text { conhecimento após a } \\
\text { capacitação. Antes } \\
\text { da capacitação, a } \\
\text { questão de maior } \\
\text { déficit de } \\
\text { conhecimento foi } \\
\text { referente a PS diante } \\
\text { de trauma com } \\
\text { avulsão dentária. } \\
\text { Após, houve maiores } \\
\text { escores quanto ao } \\
\text { manejo diante de } \\
\text { queda com } \\
\text { traumatismos } \\
\text { craniano encefálico }\end{array}$ & Não informado & $\begin{array}{l}\text { Há falta de } \\
\text { conhecimento da } \\
\text { equipe } \\
\text { multidisciplinar, } \\
\text { quanto aos PS } \\
\text { diante } \\
\text { acidentes dos } \\
\text { escolares. A } \\
\text { capacitação por } \\
\text { meio de } \\
\text { exposição } \\
\text { dialogada com } \\
\text { parte prática se } \\
\text { mostrou } \\
\text { eficiente para } \\
\text { promover } \\
\text { conhecimento }\end{array}$ \\
\hline
\end{tabular}




\begin{tabular}{|c|c|c|c|c|c|c|}
\hline & & & & e outros. & & sobre a temática. \\
\hline E31/ Croácia & $\begin{array}{l}\text { Bakarčić D, } \\
\text { Hrvatin S, } \\
\text { Maroević } \\
\text { M, Ivančić } \\
\text { Jokić N/ } \\
2017^{38}\end{array}$ & $\begin{array}{l}\text { Investigar o } \\
\text { conheciment } \\
\text { o e a atitude } \\
\text { em relação } \\
\text { ao tratamento } \\
\text { emergencial } \\
\text { de } \\
\text { traumatismo } \\
\text { dentário } \\
\text { entre } \\
\text { professores } \\
\text { do ensino } \\
\text { fundamental } \\
\text { da cidade de } \\
\text { Rijeka }\end{array}$ & $\begin{array}{l}\text { Estudo transversal realizado em } 14 \\
\text { escolas por meio da aplicação de um } \\
\text { questionário que foram distribuídos } \\
\text { durante } 2 \text { meses. } 144 \text { questionários } \\
\text { foram adequadamente preenchidos }\end{array}$ & 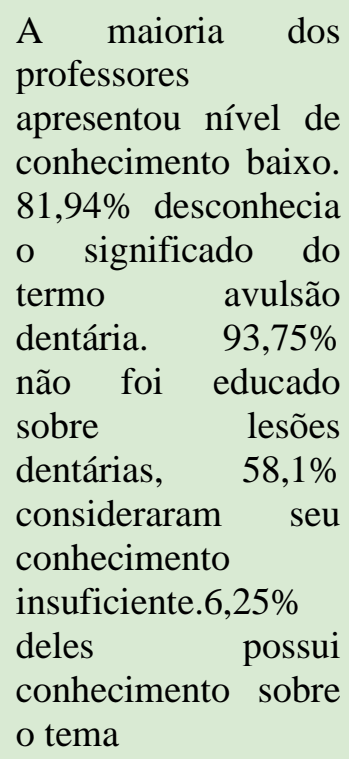 & $\begin{array}{l}\text { Consultando um } \\
\text { especialista( }(19,45 \\
\%) \text { Consultando } \\
\text { colegas( } 32 \%) ; \\
\text { Literatura } \\
\text { odontológica } \\
(9,72 \%) ; \text { Palestras } \\
(0,7 \%) ; \text { Programas } \\
\text { especializados de } \\
\text { TV / rádio(9,72\%); } \\
\text { Educação online } \\
(4,16 \%) ; \\
\text { Jornais }(0,7 \%)\end{array}$ & $\begin{array}{l}\text { O conhecimento } \\
\text { sobre o } \\
\text { gerenciamento } \\
\text { dos PS de lesões } \\
\text { dentárias é pobre } \\
\text { e inadequado } \\
\text { entre os } \\
\text { professores, mas } \\
\text { eles } \\
\text { demonstraram } \\
\text { interesse na } \\
\text { educação futura } \\
\text { sobre o tema }\end{array}$ \\
\hline E32/Eslovênia & $\begin{array}{ll}\text { Slabe } & \text { D, } \\
\text { Fink } & \text { R, } \\
\text { Dolenc } & \text { E, } \\
\text { Kvas } & \\
\text { A/2016 } & \end{array}$ & $\begin{array}{l}\text { Determinar o } \\
\text { nível de } \\
\text { conheciment } \\
\text { o de } \\
\text { professores } \\
\text { do jardim de } \\
\text { infância e } \\
\text { assistentes de } \\
\text { professores } \\
\text { do jardim de }\end{array}$ & $\begin{array}{l}\text { Foi enviado um questionário com } \\
\text { questões relacionadas a temas de saúde } \\
\text { como diabetes, convulsões febris, } \\
\text { princípios de PS, para } 45 \text { escolas de } \\
\text { jardim de infância selecionadas } \\
\text { aleatoriamente. Retornaram } 774 \\
\text { questionários respondidos, incluindo } \\
426(54,6 \%) \text { de professores e } 351 \\
(45,4 \%) \text { de assistentes }\end{array}$ & $\begin{array}{l}\text { Eles estão cientes de } \\
\text { que o conhecimento } \\
\text { sobre temas } \\
\text { relacionados à saúde } \\
\text { é necessário. Na } \\
\text { autoavaliação dos } \\
\text { conhecimentos } \\
\text { sobre os princípios } \\
\text { de saúde, } 67 \% \\
\text { consideraram como }\end{array}$ & $\begin{array}{l}\text { A maior parte de } \\
\text { seu conhecimento } \\
\text { (quase a metade) } \\
\text { foi obtida na } \\
\text { faculdade }\end{array}$ & $\begin{array}{lr}\text { Estão cientes da } \\
\text { importância de } \\
\text { se familiarizar } \\
\text { com os } \\
\text { princípios de } \\
\text { saúde para a } \\
\text { segurança das } \\
\text { crianças. } \\
\text { Participam de } \\
\text { treinamentos }\end{array}$ \\
\hline
\end{tabular}




\begin{tabular}{|c|c|c|c|c|c|c|}
\hline & & $\begin{array}{l}\text { infância de } \\
\text { vários temas } \\
\text { relacionados } \\
\text { à saúde da } \\
\text { criança }\end{array}$ & & $\begin{array}{lr}\text { muito bom } & \text { ou } \\
\text { excelente e } & 30 \% \\
\text { como bom. } & \text { No } \\
\text { entanto, } & \text { a } \\
\text { autoavaliação de } \\
\text { seus conhecimentos } \\
\text { de PS é pior }\end{array}$ & & $\begin{array}{l}\text { frequentes, } \\
\text { porém, segundo } \\
\text { as avaliações, o } \\
\text { conhecimento } \\
\text { deles de PS } \\
\text { básicos é baixo }\end{array}$ \\
\hline E33/Espanha & $\begin{array}{l}\text { Alba } \\
\text { Martín } \\
\text { R/2015 }\end{array}$ & $\begin{array}{l}\text { Avaliar o } \\
\text { aumento do } \\
\text { conheciment } \\
\text { o em PS dos } \\
\text { professores } \\
\text { da instituição } \\
\text { de ensino } \\
\text { fundamental, } \\
\text { após uma } \\
\text { intervenção } \\
\text { educacional }\end{array}$ & $\begin{array}{l}\text { Estudo quase experimental realizado } \\
\text { com } 15 \text { professores de uma escola } \\
\text { pública de ensino fundamental de } \\
\text { Córdoba. Consistiu em três fases } \\
\text { presenciais: } 1^{\circ} \text { aplicação de pré- } \\
\text { questionário; } 2^{\circ} \text { intervenção } \\
\text { educacional teórico-prática por } \\
\text { uma semana e } 3^{\circ} \text { aplicação de pós- } \\
\text { questionário }\end{array}$ & $\begin{array}{l}46,7 \% \text { receberam } \\
\text { anteriormente algum } \\
\text { tipo de informação } \\
\text { sobre PS. 100\% } \\
\text { sabem qual é a } \\
\text { definição de PS. } \\
\text { Apresentam } \\
\text { conceitos errôneos } \\
\text { sobre como tratar } \\
\text { feridas e não sabem } \\
\text { como funciona o } \\
\text { desfibrilador } \\
\text { externo. Observou- } \\
\text { se aumento no } \\
\text { conhecimento após a } \\
\text { intervenção }\end{array}$ & Não informado & $\begin{array}{l}\text { O conhecimento } \\
\text { que os } \\
\text { professores } \\
\text { apresentam } \\
\text { sobre PS antes } \\
\text { da intervenção } \\
\text { são deficientes. } \\
\text { Foi notado o } \\
\text { interesse em } \\
\text { receber } \\
\text { conhecimento de } \\
\text { PS. Em geral, } \\
\text { todos aumentam } \\
\text { seu } \\
\text { conhecimento } \\
\text { após a } \\
\text { intervenção }\end{array}$ \\
\hline
\end{tabular}




\begin{tabular}{|c|c|c|c|c|c|c|}
\hline E34/Espanha & $\begin{array}{l}\text { Carral San } \\
\text { Laureano F, } \\
\text { Gutiérrez } \\
\text { Manzanedo } \\
\text { JV, Moreno } \\
\text { Vides P, de } \\
\text { Castro } \\
\text { Maqueda } \\
\text { G, } \\
\text { Fernández } \\
\text { Santos JR, } \\
\text { Ponce } \\
\text { González } \\
\text { JG, et } \\
\text { al/2018 }\end{array}$ & $\begin{array}{l}\text { Avaliar as } \\
\text { atitudes e } \\
\text { percepções } \\
\text { dos } \\
\text { professores } \\
\text { sobre a } \\
\text { preparação } \\
\text { de escolas } \\
\text { públicas de } \\
\text { ensino do } \\
\text { fundamental } \\
\text { e médio na } \\
\text { área } \\
\text { Hospital de } \\
\text { Universitário } \\
\text { de Puerto } \\
\text { Real para } \\
\text { cuidar de } \\
\text { estudantes } \\
\text { com diabetes } \\
\text { mellitus tipo } \\
1 \text { (DM1) }\end{array}$ & $\begin{array}{l}\text { Estudo observacional descritivo. Foram } \\
\text { analisadas respostas de um questionário } \\
\text { de atitude e percepção sobre a } \\
\text { preparação das escolas para o } \\
\text { atendimento de alunos com DM1. Um } \\
\text { total de } 765 \text { professores na área do } \\
\text { Hospital Universitário de Puerto Real } \\
\text { foram selecionados }\end{array}$ & $\begin{array}{l}\text { Apenas } 0,8 \% \text { dos } \\
\text { entrevistados haviam } \\
\text { tido algum tipo de } \\
\text { treinamento } \\
\text { específico para PS } \\
\text { sobre diabetes. } \\
9,4 \% \text { dos } \\
\text { professores } \\
\text { consideram que seu } \\
\text { centro educacional é } \\
\text { capaz de atender } \\
\text { emergências } \\
\text { diabéticas }\end{array}$ & Não informado & $\begin{array}{l}\text { Resultados } \\
\text { sugerem que os } \\
\text { professores não } \\
\text { foram treinados } \\
\text { especificamente } \\
\text { no atendimento } \\
\text { de pacientes com } \\
\text { DM1 } \\
\text { percebem que } \\
\text { não estão } \\
\text { qualificados para } \\
\text { atender } \\
\text { emergências } \\
\text { diabéticas }\end{array}$ \\
\hline E35/ Espanha & $\begin{array}{l}\text { Abelairas- } \\
\text { Gómez C, } \\
\text { Carballo- } \\
\text { Fazanes A, } \\
\text { Martínez- } \\
\text { Isasi S, } \\
\text { López- } \\
\text { García S, }\end{array}$ & $\begin{array}{l}\text { Avaliar o } \\
\text { conheciment } \\
\text { o de PS de } \\
\text { professores } \\
\text { do ensino } \\
\text { fundamental } \\
\text { e pré-escolar } \\
\text { e de pais de } \\
\text { crianças }\end{array}$ & $\begin{array}{l}\text { Foi utilizado um questionário composto } \\
\text { por } 4 \text { seções que foi enviado por e-mail } \\
\text { no formato Google Forms e aplicado a } \\
470 \text { pessoas }\end{array}$ & $\begin{array}{l}\text { Mais da metade } \\
\text { afirmaram ter } \\
\text { conhecimento de PS. } \\
41 \text { ensinaram } \\
\text { conteúdo sobre PS e } \\
161 \text { alegaram ter } \\
\text { conhecimento de PS. } \\
\text { Nenhum respondeu } \\
\text { corretamente a todas }\end{array}$ & Não informado & $\begin{array}{l}\text { Embora } \\
\text { maioria dos } \\
\text { professores e } \\
\text { pais tenham } \\
\text { recebido algum } \\
\text { treinamento em } \\
\text { PS eles possuem } \\
\text { uma falha ao } \\
\text { responder }\end{array}$ \\
\hline
\end{tabular}




\begin{tabular}{|c|c|c|c|c|c|c|}
\hline & $\begin{array}{l}\text { Rico-Díaz } \\
\text { J, } \\
\text { Rodríguez- } \\
\text { Núnez } \\
\text { A/2019 }\end{array}$ & $\begin{array}{l}\text { nessas etapas } \\
\text { da educação }\end{array}$ & & $\begin{array}{l}\text { as perguntas sobre } \\
\mathrm{RC} \text { em bebês e } \\
\text { crianças pequenas }\end{array}$ & & $\begin{array}{l}\text { corretamente às } \\
\text { perguntas } \\
\text { relacionadas a } \\
\text { SBV }\end{array}$ \\
\hline E36/ Espanha & $\begin{array}{l}\text { Zunino M, } \\
\text { Pantoja } \\
\text { MB, Villar } \\
\text { AB } / 2020^{43}\end{array}$ & $\begin{array}{l}\text { Determinar o } \\
\text { grau de } \\
\text { conheciment } \\
\text { o dos pais / } \\
\text { responsáveis, } \\
\text { professores e } \\
\text { treinadores } \\
\text { sobre o } \\
\text { manejo } \\
\text { primário da } \\
\text { avulsão } \\
\text { dentária na } \\
\text { população } \\
\text { infantil }\end{array}$ & $\begin{array}{l}\text { Estudo observacional transversal. } \\
\text { Aplicado questionário sobre o } \\
\text { conhecimento de gestão de } \\
\text { emergências em caso de avulsão } \\
\text { dentária em } 546 \text { indivíduos }\end{array}$ & $\begin{array}{l}81 \% \text { dos } \\
\text { entrevistados } \\
\text { desconheciam o } \\
\text { termo avulsão. O } \\
\text { grupo de professores } \\
\text { mostrou pouco } \\
\text { conhecimento no } \\
\text { manejo da avulsão. }\end{array}$ & Não informado & \begin{tabular}{lr}
\multicolumn{2}{c}{ Pais/responsávei } \\
s, professores, \\
treinadores $\mathrm{e}$ \\
pessoal não \\
docente não têm \\
o conhecimento \\
necessário para \\
ajudar r uma \\
criança rue \\
sofreu \\
avulsão dentária
\end{tabular} \\
\hline E37/ Grécia & $\begin{array}{l}\text { Kampra M, } \\
\text { Tzerakis } \\
\text { NG, Losidis } \\
\text { S, Katsarou } \\
\text { E, Voudris } \\
\text { K, } \\
\text { Mastroyian } \\
\text { ni S, et } \\
\text { al/2016 }\end{array}$ & $\begin{array}{l}\text { Explorar as } \\
\text { fontes de } \\
\text { conheciment } \\
\text { o fornecidas } \\
\text { pelos } \\
\text { educadores } \\
\text { das escolas } \\
\text { primárias e } \\
\text { secundárias } \\
\text { gregas } \\
\text { relacionadas } \\
\text { com }\end{array}$ & $\begin{array}{l}\text { Questionário semiestruturado foi } \\
\text { distribuído em escolas públicas } \\
\text { primárias e secundárias. } 96 \text { escolas } \\
\text { concordaram em participar e taxa de } \\
\text { resposta ao questionário foi de apenas } \\
22 \%\end{array}$ & $\begin{array}{lr}81 \% & \text { tinha } \\
\text { conhecimento sobre } \\
\text { epilepsia. 92,8\% se } \\
\text { sentiram } \\
\text { completamente } \\
\text { destreinados para } \\
\text { administrar }\end{array}$ & $\begin{array}{l}29,7 \% \\
\text { experiências } \\
\text { pessoais; } 22,7 \% \text { da } \\
\text { internet; } 2,8 \% \\
\text { seminários; } 11,5 \% \\
\text { aprenderam por } \\
\text { meio de todos } \\
\text { esses itens já } \\
\text { citados e } 33,3 \% \\
\text { por outras fontes. }\end{array}$ & $\begin{array}{l}\text { Os educadores } \\
\text { precisam de } \\
\text { informações } \\
\text { adequadas sobre } \\
\text { epilepsia e } \\
\text { histórias } \\
\text { médicas com } \\
\text { treinamento } \\
\text { apropriado sobre } \\
\text { como lidar com } \\
\text { incidentes } \\
\text { convulsivos. }\end{array}$ \\
\hline
\end{tabular}


epilepsia, PS

em caso de

convulsões. epilépticas.

\begin{tabular}{|c|c|c|c|c|c|c|}
\hline E38/Grécia & $\begin{array}{l}\text { Tzimpoulas } \\
\text { N, Markou } \\
\text { M, Zioutis } \\
\text { V, } \\
\text { Tzanetakis } \\
\text { GNl/2020 }\end{array}$ & $\begin{array}{l}\text { Avaliar o } \\
\text { nível de } \\
\text { conheciment } \\
\text { o e a atitude } \\
\text { de um grupo } \\
\text { de } \\
\text { professores } \\
\text { da escola } \\
\text { primária } \\
\text { grega quanto } \\
\text { aos PS de } \\
\text { traumatismo } \\
\text { dentário } \\
\text { discutir } \\
\text { meios para a } \\
\text { melhoria } \\
\text { desse } \\
\text { conheciment } \\
\text { o no futuro }\end{array}$ & $\begin{array}{l}\text { Estudo descritivo transversal realizado } \\
\text { com } 276 \text { professores de escolas } \\
\text { primárias por meio da aplicação } \\
\text { de questionários com } \\
\text { sobre características questões } \\
\text { atitude e demográficas, } \\
\text { gerenciamento de PS de lesões } \\
\text { dentárias traumáticas }\end{array}$ & $\begin{array}{lr}77,2 \% & \text { afirmaram } \\
\text { nunca ter recebido } \\
\text { treinamento prévio } \\
\text { de PS } & \text { em } \\
\text { traumatismos } \\
\text { dentários } \\
\text { informações } & \text { nem } \\
\text { tais lesões. Apenas } \\
\text { 23,9\% acreditavam } \\
\text { na capacidade de } \\
\text { ajudar durante uma } \\
\text { situação urgente de } \\
\text { lesões dentárias } \\
\text { traumáticas } \\
\text { escola na }\end{array}$ & $\begin{array}{l}77,2 \quad \% \quad \text { não } \\
\text { possuíam fonte } \\
\text { alguma em PS; } \\
9,1 \% \text { de cursos de } \\
\text { PS; 7,2\% de } \\
\text { treinamentos para } \\
\text { especialistas; } 5,1 \% \\
\text { de folhetos } \\
\text { informativos; e } 4,7 \\
\% \text { de pesquisas da } \\
\text { internet }\end{array}$ & $\begin{array}{l}\text { O nível de } \\
\text { conhecimento } \\
\text { dos professores } \\
\text { sobre PS durante } \\
\text { lesões dentárias } \\
\text { traumáticas é } \\
\text { limitado. Existe } \\
\text { uma conexão } \\
\text { positiva entre o } \\
\text { nível de } \\
\text { conhecimento de } \\
\text { PS em trauma } \\
\text { dentário e a } \\
\text { experiência de } \\
\text { ensino }\end{array}$ \\
\hline E39/ Itália & $\begin{array}{l}\text { Savarese G, } \\
\text { Carpinelli } \\
\text { L, D'Elia } \\
\text { D, Coppola } \\
\text { G/ 2015 }\end{array}$ & $\begin{array}{l}\text { Examinar as } \\
\text { informações } \\
\text { e } \\
\text { conheciment } \\
\text { os sobre } \\
\text { epilepsia, as } \\
\text { representaçõ } \\
\text { es da }\end{array}$ & 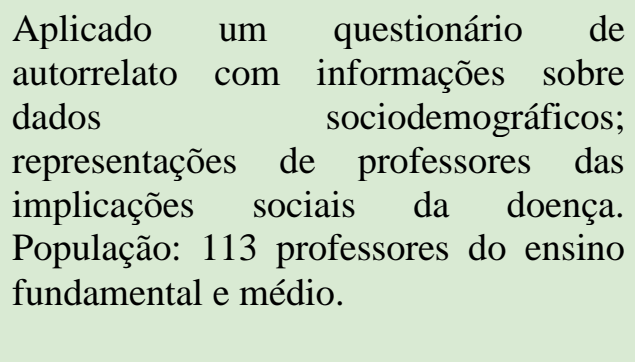 & $\begin{array}{l}\text { Professores com } \\
\text { mais de } 10 \text { anos de } \\
\text { experiência } \\
\text { profissional } \\
\text { demonstraram um } \\
\text { conhecimento } \\
\text { adequado sobre } \\
\text { epilepsia.. Professor }\end{array}$ & Não informado & $\begin{array}{l}\text { Existem lacunas } \\
\text { significativas } \\
\text { dentro do } \\
\text { conhecimento } \\
\text { geral dos } \\
\text { professores, no } \\
\text { seu impacto nos } \\
\text { ambientes }\end{array}$ \\
\hline
\end{tabular}




\begin{tabular}{|c|c|c|c|c|c|c|}
\hline & & $\begin{array}{l}\text { qualidade de } \\
\text { vida de } \\
\text { crianças com } \\
\text { epilepsia. }\end{array}$ & & $\begin{array}{l}\text { es mostraram um } \\
\text { conhecimento baixo } \\
\text { sobre administração } \\
\text { de PS na epilepsia. }\end{array}$ & & $\begin{array}{l}\text { educacionais e o } \\
\text { cuidado } \\
\text { apropriado de } \\
\text { epilepsia na sala } \\
\text { de aula }\end{array}$ \\
\hline E40/ Austrália & $\begin{array}{lr}\text { Luckie } & \text { K, } \\
\text { Saini } & \text { B, } \\
\text { Soo YY, } & \text { YYitikos V, } \\
\text { Collins } & \text { JC, } \\
\text { Moles RJ/ } \\
2018^{47}\end{array}$ & $\begin{array}{l}\text { Testar a } \\
\text { hipótese de } \\
\text { que o } \\
\text { treinamento } \\
\text { de } \\
\text { habilidades } \\
\text { baseado em } \\
\text { cenários é } \\
\text { mais eficaz } \\
\text { do que o } \\
\text { treinamento } \\
\text { do sozinho } \\
\text { conheciment } \\
\text { o sara } \\
\text { para } \\
\text { melhorar as } \\
\text { habilidades } \\
\text { de PS em } \\
\text { asma do } \\
\text { pessoal da } \\
\text { escola. }\end{array}$ & $\begin{array}{l}204 \text { pessoas de escolas primárias foram } \\
\text { alocadas em } 1 \text { dos três grupos para } \\
\text { comparar os conhecimentos e } \\
\text { habilidades em PS em asma. Grupo 1: } \\
\text { submetido a treinamento convencional; } \\
\text { grupo } 2 \text { submetido a treinamento } \\
\text { baseado em cenário; grupo } 3 \text { teve } \\
\text { combinação dos dois. }\end{array}$ & $\begin{array}{l}77 \% \text { dos } \\
\text { participantes eram } \\
\text { professores. Havia } \\
\text { um alto } \\
\text { conhecimento de } \\
\text { base que melhorou } \\
\text { minimamente, } \\
\text { independentemente } \\
\text { do treinamento } \\
\text { fornecido. } \\
\text { treinamento baseado } \\
\text { em cenários teve um } \\
\text { impacto significativo } \\
\text { na capacidade do } \\
\text { participante de } \\
\text { administrar PS. }\end{array}$ & Não informado & $\begin{array}{l}\text { O conhecimento } \\
\text { dos PS na asma } \\
\text { melhorou, no } \\
\text { geral. As } \\
\text { habilidades e } \\
\text { competências de } \\
\text { PS foram } \\
\text { significativamen } \\
\text { te superiores nos } \\
\text { participantes que } \\
\text { tiveram o } \\
\text { treinamento. }\end{array}$ \\
\hline
\end{tabular}

Fonte: Os autores. 
Dos 40 artigos selecionados, 30 (75\%) estavam disponíveis na língua inglesa, seis (15\%) na língua portuguesa e quatro $(10 \%)$ na língua espanhola. Sete $(17,5 \%)$ dos artigos foram publicados no ano de 2015, quatro (10\%) em 2016, oito (20\%) em 2017, 9 $(22,5 \%)$ em 2018, seis (15\%) em 2019 e seis (15\%) foram publicados até julho de 2020 (Figura 2).

Os estudos foram oriundos de 17 diferentes nacionalidades, sendo 18 (45\%) realizados no continente asiático, 10 (25\%) no continente europeu, sete $(17,5 \%)$ dos artigos selecionados eram de origem americana, 5 $(12,5 \%)$ dos artigos eram africanos cujo país com maior frequência de publicação foi a Etiópia apresentando 3 artigos (7,5\%) e 1 $(2,5 \%)$ estudo foi realizado na Oceania, especificamente na Austrália. Os países que apresentaram maior quantidade de publicações no tema foram Arábia Saudita com oito artigos (20\%), seguido do Brasil com sete $(17,5 \%)$ e Espanha e Irã com quatro estudos cada (10\%).

Os artigos selecionados foram escritos por profissionais, majoritariamente, da área da saúde, sendo $17(42,5 \%)$ de medicina, 10 (25\%) de odontologia, $7(17,5 \%)$ de enfermagem, $1(2,5 \%)$ de farmácia. Houve ainda $5(12,5 \%)$ estudos realizados em parceria entre áreas, sendo 2 (5\%) enfermagem e medicina, 1 (2,5\%) enfermagem e educação física, 1 (2,5\%) medicina e farmácia, 1 (2,5\%) Ciências da Saúde.

Os professores abordados nas pesquisas eram de diferentes níveis da educação básica. Dos 40 artigos, 12 (30\%) investigaram conhecimento dos professores do ensino fundamental e médio, 12 (30\%) somente do ensino fundamental, 4 (10\%) do ensino infantil, $2(5 \%)$ somente do ensino médio, 2 (5\%) abordaram professores do ensino infantil, fundamental e médio, 2 (5\%) do ensino infantil e fundamental, $1(2,5 \%)$ do ensino especializado e 5 artigos (12,5\%) não especificaram o nível de ensino. De maneira geral, os conhecimentos dos professores sobre primeiros socorros foram considerados baixos e insuficientes, contudo, estudos de países como o Irã e a Austrália apresentaram melhores índices de conhecimento. O Irã apresentou conhecimento moderado, ao passo que a Austrália apresentou alto conhecimento. Dentre os 40 artigos analisados, 21 deles $(52,5 \%)$ trouxeram informações em relação aos treinamentos prévios em primeiros socorros pelos professores, enquanto 19 $(47,5 \%)$ não apresentaram essa informação. A média de professores que tiveram treinamentos em primeiros socorros foi de $29,9 \%$.

No tocante aos fatores associados ao conhecimento em PS (Primeiros Socorros), dos 40 artigos analisados, 13 apontaram a faixa etária acima dos 40 anos como um fator para maior conhecimento, seguido por anos 
de experiência e possuir treinamento prévio para PS, apontados por 10 e 7 artigos respectivamente. Apenas 4 artigos identificaram o sexo como fator determinante para um maior conhecimento em PS. Dos estudos que investigaram o interesse dos professores em adquirir ou aumentar o conhecimento sobre primeiros socorros (40\%), a taxa de interesse foi, em geral, superior a $70 \%$ entre os participantes dos estudos. Em relação às fontes de conhecimentos sobre primeiros socorros dos professores, 25 estudos $(62,5 \%)$ não investigaram esse tópico e 15 (37,5 \%) abordaram quais as procedências das informações que estes profissionais têm sobre esse tema. As fontes que aparecem com mais frequência são internet, mídias e meios de comunicação em massa, seguido por conhecimentos oriundos de colegas, amigos e parentes. Outras fontes menos citadas foram leituras, experiências pessoais e maternas, mitos populares, palestras e outros meios. As informações oriundas de profissionais da saúde, médicos e enfermeiros aparecem, porém com baixas porcentagens com resultados que variam de $2,3 \%$ a $53,1 \%$ de entrevistados que tinham como fonte sobre PS o pessoal da saúde. Apenas um estudo trouxe que o conhecimento dos participantes veio dos ensinamentos da formação acadêmica.

Dentre os artigos analisados 15 $(37,5 \%)$ abordaram questões relacionadas a primeiros socorros às pessoas que sofreram lesões por esporte, desmaios, picadas de inseto, dificuldades respiratórias, fraturas, ressuscitação cardiopulmonar, avulsão dentária, quedas, queimaduras, convulsões rebaixamento do nível de consciência, retirada de corpo estranho das vias aéreas e atendimento a pessoas com doenças crônicas como diabetes. O principal país que apresentou maior número de estudos relacionados à investigação do conhecimento dos professores sobre primeiros socorros em geral foi o Brasil com cinco estudos dentre os 15 sobre esse tema. Foram também identificados $12(30 \%)$ artigos que tratavam especificamente sobre primeiros socorros a vítimas com convulsão e/ou epilepsia com estudos asiáticos, representados principalmente pela Arábia Saudita com três pesquisas entre as 12, africanos e europeus. Não foram encontrados estudos brasileiros sobre essa temática pelos métodos de busca adotados neste trabalho. A investigação sobre conhecimento de primeiros socorros aplicados a traumatismo dentário ou avulsão dentária $\begin{array}{llllll}\text { apareceu em } & 10 & (25 \%) & \text { artigos } & \text { dos } & 40\end{array}$ avaliados, sendo estudos do Brasil e da Arabia Saudita com maior frequência, com um total de dois de cada nacionalidade. Os primeiros socorros aplicados à asma apareceram em dois (5\%) artigos do total, cuja origem é australiana e árabe. Apenas um $(2,5 \%)$ artigo, espanhol, tratou sobre o conhecimento de primeiros socorros aplicados a pessoas com diabetes mellitus tipo 1 . 


\section{DISCUSSÃO}

Os 40 artigos analisados nesta revisão possuem diferentes origens, o que amplia o olhar sobre a temática discutida. Dentre os artigos utilizados, a maioria foi de origem asiática e europeia, porém quando se leva em consideração a nacionalidade, o Brasil aparece em segundo lugar na quantidade de publicações analisadas. Essa quantidade, um pouco maior de publicações sobre o tema no Brasil, pode ser devido à adequação nacional da Lei Lucas/Lei No13.722, além de que, futuramente, serão ainda necessários estudos nesse campo que poderão ser utilizados como indicadores de eficiência da lei ${ }^{(6)}$. No entanto, ainda considera-se incipiente a produção de estudos nessa temática no Brasil, e esta revisão aponta algumas áreas para futuras pesquisas.

Notou-se nesta pesquisa que, de maneira geral, o nível de conhecimento dos professores sobre primeiros socorros foi baixo ou insuficiente, corroborando com os resultados apresentados na revisão integrativa a qual identificou níveis baixos de conhecimento dos professores nos testes pré intervenção $^{(48)}$. Vários estudos, de diferentes nacionalidades vêm apontando o baixo nível de conhecimento em primeiros socorros por parte dos professores ${ }^{(49-55)}$. Os países que obtiveram resultados satisfatórios foram Irã e Austrália, e foi apontado como bom resultado nas Filipinas ${ }^{(53)}$. É importante destacar, que cada estudo, em cada país teve metodologia diferente para quantificar e qualificar o conhecimento dos professores. Foi identificado também que o ensino fundamental foi o mais abordado, evidenciando a importância de avaliar estes conhecimentos de professores de outros níveis de educação. Torna-se preocupante, que no Brasil, apesar de existir legislação que obriga a capacitação em primeiros socorros, ainda se observa baixo conhecimento. Mais estudos são necessários para avaliar o impacto da Lei Lucas no Brasil depois de dois anos da sua implantação ${ }^{(6)}$.

Apesar do baixo conhecimento geral encontrado nos estudos, a disposição em adquirir conhecimento e dominar técnicas de primeiros socorros ficou evidente entre os professores. Esse interesse aponta para uma oportunidade de qualificar essa população por meio de programas de educação em saúde direcionados para primeiros socorros à crianças e adolescentes em ambiente escolar por meio da oferta de cursos, workshops e palestras com tema para orientá-los sobre esse assunto. Pois, estudos comprovam que intervenções educativas melhoram 0 conhecimento e habilidades dos docentes em identificar um acidente, solicitar ajuda e atuar frente a diferentes cenários que necessitam desse primeiro atendimento, uma vez que o socorro imediato pode ser fundamental no prognóstico clínico do paciente, evitando lesões irreversíveis ${ }^{(2 ; 48)}$. 
Não foi identificado em nenhum dos estudos políticas de educação em saúde para profissionais da educação, principalmente no que tange primeiros socorros. Esse é um dado preocupante, visto que crianças e adolescentes ficam altamente expostos à riscos de acidentes dentro das instituições de ensino e os agentes de educação não estão preparados para socorrer as vítimas adequadamente ${ }^{(56)}$. Mesmo entre os profissionais que detém algum conhecimento sobre primeiros socorros, muitos não se consideram capazes de oferecer assistência corretamente.

Em relação aos fatores associados aos conhecimentos sobre primeiros socorros, houve uma predominância dos fatores: idade, anos de experiência e treinamento prévio para PS. Esses três componentes foram identificados como preditores para um aumento do nível de conhecimento dos professores. Dados semelhantes foram encontrados no estudo em que quanto maior os anos de experiência do professor, maior o seu conhecimento em primeiros socorros ${ }^{(57)}$. Não obstante, outro estudo identificou que todos os professores que possuíam um treinamento prévio para PS obtiveram conhecimento significativamente maior do que aqueles que não possuíam treinamento ${ }^{(51)}$ Esta revisão evidenciou que internet, mídia, meios de comunicação em massa, experiências pessoais e maternas são as principais fontes de conhecimento sobre o PS dos professores. Essas fontes possuem o risco de estarem incorretas ou desatualizadas e foi observado que profissionais da saúde e literatura científica, foram os meios menos citados. Os profissionais da saúde desempenham o importante papel de educadores em saúde para a população que desconhece sobre $\mathrm{PS}^{(1)}$. Além disso, são os profissionais mais capacitados para ministrar esses conhecimentos e poderiam fazê-los desde a formação dos professores.

A inserção de profissionais da saúde como moderadores dessa capacitação pode ser realizada por meio de parcerias em projetos de extensão dos cursos de medicina e enfermagem junto às escolas, e também pela integração dos aparelhos do município (unidades de assistência à saúde e escolas), intercambiando os profissionais de saúde, enfermeiros e médicos dos programas saúde da família para capacitações nas escolas dos municípios. Parcerias público-privadas também devem ser estimuladas, aumentando as possibilidades da inserção de profissionais de saúde na capacitação de professores em primeiros socorros.

Além disso, faz-se necessário rever as grades curriculares de formação de professores, para identificar as lacunas em primeiros socorros $^{(7-8)}$. Ainda, para garantir um profissional com conhecimento adequado em primeiros socorros na escola, o preparo do professor nessa área, pode ser uma das prerrogativas dos processos seletivos, melhorando assim a segurança interna. 
Dos artigos analisados, foi identificada frequência significativa de pesquisas que investigaram especificamente $o$ conhecimento sobre primeiros socorros direcionados a convulsões e/ou epilepsia sendo $30 \%$ de todos os artigos selecionados. Os estudos eram oriundos principalmente da Ásia, seguido de pesquisas da África e da Europa.

O conhecimento dos professores da educação básica sobre PS, com ênfase nas crises convulsivas, e apenas 32\% cursaram alguma disciplina sobre PS durante a graduação $^{(7)}$. A falta de conhecimento é expressa em respostas incorretas dos professores a questionários de avaliação do conhecimento, como abrir a boca do paciente e colocar um pano para prevenir que o aluno morda a língua ${ }^{(7)}$.

A epilepsia atinge em torno de 50 milhões de pessoas no mundo e trata-se de uma doença neurológica crônica que possui como características episódios de convulsões frequentes. A maioria das pessoas, cerca de $80 \%$, as quais possuem esse diagnóstico, moram em países em desenvolvimento e com poucos recursos, o que contribui para dificuldade de acessar os serviços de saúde e consequentemente os profissionais e o tratamento $^{(55,58)}$. Diante deste contexto, os professores da educação básica quando cientes e com o conhecimento adequado para prestação de primeiros socorros em episódios de convulsão podem servir como agentes de prevenção de possíveis complicações e sequelas decorrentes desta situação.

A prevalência dessa doença no território brasileiro é de 7,8 para cada 1000 habitantes. Em comparação com os países ocidentais, existe um aumento nas taxas de incidência e prevalência da epilepsia nos países da América Latina, os quais inclui o Brasil $^{(58)}$. Neste presente estudo não foi identificado nenhuma pesquisa de origem brasileira direcionada para o conhecimento de professores sobre esse assunto em específico. Além disso, a prestação de atendimento de primeiros socorros de forma eficiente para pacientes com epilepsia, os quais apresentam convulsões, contribui para evitar surgimento de lesões ou complicações, já que o socorro imediato pode salvar vidas ${ }^{(55,59)}$.

Dos 40 estudos selecionados nesta pesquisa, $25 \%$ avaliaram o conhecimento especificamente sobre avulsão dentária ou traumatismo dentário. Essa temática é de grande importância no ambiente escolar, visto que as crianças se envolvem em muitas atividades esportivas ou recreativas neste cenário, no qual passam grande parte do seu tempo, e, portanto, se tornam sujeitas ao risco de sofrer um traumatismo. Ademais, estudos comprovam que devido a falta de informação da população sobre as medidas de PS necessárias para essas situações, muitos dentes traumatizados podem ser irrecuperáveis ou apresentar um prognóstico 
danoso, resultando em desfecho insatisfatório $^{(60)}$.

\section{CONCLUSÕES}

Foi predominante o baixo nível de conhecimento sobre primeiros socorros entre professores da educação básica e os fatores associados a melhores níveis de conhecimento foram idade avançada, treinamentos prévios e experiência profissional. As principais fontes de conhecimento dos professores são pouco confiáveis e o conhecimento intermediado por profissionais da saúde foi pouco referido. Investimentos em políticas de formação de professores em primeiros socorros e da parceria saúde-educação devem ser implementados para aumentar o conhecimento dos professores e garantir maior segurança no ambiente escolar.

A partir das reflexões dos resultados deste estudo, observa-se que ele apresenta grandes contribuições para o ensino, pesquisa e extensão nas áreas da educação e da saúde, considerando que o conhecimento dos professores da educação básica é baixo e insuficiente. A enfermagem, a qual apresenta conhecimento sobre o tema, pode surgir nesse contexto como um caminho para a oferta desse ensino a esses profissionais com o objetivo de os treinarem para essas situações que podem acontecer no ambiente escolar ou em outros cenários, contribuindo, portanto, para a efetivação do programa, proposto pelo Ministério da Saúde e Ministério da Educação em 2007, intitulado Programa Saúde na Escola visto que um dos componentes é a Educação Permanente e Capacitação dos Profissionais da Educação ${ }^{(61)}$.

\section{REFERÊNCIAS}

1.Ferreira M, Pereira AS, de Souto, CG, Virgínio, N, Silva Júnior J.N, dos Santos A. O leigo em primeiros socorros: uma revisão integrativa. Rev. Ciênc. Saúde Nova Esperança. 2017;15(3): 12-20. Disponível em: https://revista.facene.com.br/index.php/revistane/a rticle/view/64. Acesso em 05 de set. de 2020

2Brito JG, Oliveira IP, Godoy CB, França AP. Efeito de capacitação sobre primeiros socorros em acidentes para equipes de escolas de ensino especializado. Rev. Bras. Enferm. [Internet]. 2020 [cited 2021 May 12] ; 73( 2 ): e20180288. Available from: http://www.scielo.br/scielo.php?script=sci_arttext $\&$ pid $=$ S0034-71672020000200151\&lng=en. Epub Feb 17, 2020. https://doi.org/10.1590/00347167-2018-0288.

3.Calandrim LF, Santos AB, Oliveira LR, Massaro LG, Vedovato CL, Boaventura AP. Primeiros socorros na escola: treinamento de professores e funcionários/ First aid at school: teacher and staff training. Rev. Rene. 2017;18(3): 292-99. Disponível em: <http://periodicos.ufc.br/rene/article/view/20044> - Acesso em: 08 maio 2020. DOI: 10.15253/2175-6783.2017000300002.

4.Silva LGS, Costa JB, Furtado LGS, Tavares JB, Costa JLD. Primeiros socorros e prevenção de acidentes no ambiente: intervenção em unidade de ensino. 2017; [cited 2021 May 22]; 8(3):25-9. Available from: https://www.ncbi.nlm.nih.gov/pmc/articles/PMC5 031068/ doi:_https://doi.org/10.5205/1981-8963v12i5a234592p1444-1453-2018

5.Filho AR, Pereira NA, Leal I, Anjos Q da S, Loose JTT. A Importância do Treinamento de Primeiros Socorros no Trabalho. Rev Saberes, Rolim Moura [Internet]. 2015; [cited 2021 May 12]; 3:115. Available from: https://facsaopaulo.edu.br/wpcontent/uploads/sites/16/2018/05/ed3/10.pdf

6.Brasil. Lei $\mathrm{N}^{\mathrm{o}} 13.722$ de 4 de outubro de 2018. Torna obrigatória a capacitação em noções básicas de primeiros socorros de professores e funcionários de estabelecimentos de ensino 
públicos e privados de educação básica e de estabelecimentos de recreação infantil. Diário Oficial da União [Internet]. 2018 . Disponível em: https://presrepublica.jusbrasil.com.br/legislacao/6 34357752/lei-13722-18 Acesso em: 09 maio de 2020.

7. Cabral EV, Oliveira MF. Primeiros socorros na escola: conhecimento dos professores. Revista Práxis. 2019; 11(22): 97-106. Disponível em: https://periodicos.uff.br/ensinosaudeambiente/arti cle/view/21255. Acesso em: 14 janeiro 2021. DOI:

https://doi.org/10.22409/resa2017.v10i1.a21255

8.Costa OC Nunes LA. Nível de conhecimento em Primeiros Socorros dos Professores de Educação Física das Escolas de São Luís/MA. Revista Ceuma Perspectivas. 2016; 28(2). Disponível em: http://www.ceuma.br/portalderevistas/index.php/ RCCP/article/view/51. Acesso em: 09 mar. 2021. DOI: https://doi.org/10.24863/rccp.v28i2.51

9. Taranath M, Senaikarasi RM, Manchanda K. Assessment of knowledge and attitude before and after a health education program in East Madurai primary school teachers with regard to emergency management of avulsed teeth. J Indian Soc Pedod Prev Dent [Internet]. 2017;35(1)63-67. Available from: https://pubmed.ncbi.nlm.nih.gov/28139485/ doi:10.4103/0970-4388.199218

10. Alqahtani, JM. Knowledge and practice of schoolteachers towards students with epilepsy in Khamis Mushate, Southern Saudi Arabia. J Fam Community Med [serial online]. 2015; 22(3): 1638. Available from: https://www.jfcmonline.com/text.asp?2015/22/3/1 63/163034. Acesso em: 3 maio 2020. DOI: $10.4103 / 2230-8229.163034$

11. Al Aloola NA, Saba M, Nissen L, Alewairdhi HA, Alaloola A, Saini B. Development and evaluation of a school-based asthma educational program. J Asthma. 2017;54(4):419-429. doi:10.1080/02770903.2016.1218015

12. Alsadhan_SA, Alsayari_NF, Abuabat_MF. Teachers' knowledge concerning dental trauma and its management in primary schools in Riyadh, Saudi Arabia. Int Dent J, 2018; 68(5); 306-313, 2018. Available from: https://pubmed.ncbi.nlm.nih.gov/29468667/.

Acesso em: 3 maio 2020.doi: 10.1111/idj.12385.

13. Al-Harbi AF, Alsaid LA, PARAMEASWARI PJ. Primary school female teachers' knowledge, attitude, and practice toward students with epilepsy in Riyadh, Saudi Arabia. J Family Med
Prim Care, 2018, 7( 2): 331-336. Available from: https://www.ncbi.nlm.nih.gov/pmc/articles/PMC6 060931/. Acesso em: 7 maio 2020. doi:10.4103/jfmpc.jfmpc_58_18

14. Al Gharsan M, Alarfaj I. Knowledge and practice of secondary school teachers about first aid. J Family Med Prim Care. 2019;8(5):15871593. doi:10.4103/jfmpc.jfmpc_76_19

15. AlYahya IA, Almohsen HA, AlSaleem IA, Al-Hamid MM, Arafah AM, Al Turki YA, et al. Assessment of knowledge, attitude, and practice about first aid among male school teachers and administrators in Riyadh, Saudi Arabia. J Family Med Prim Care. 2019 Feb;8(2):684-688. Available from: https://www.ncbi.nlm.nih.gov/pmc/articles/PMC6 436304/. Acesso em: 15 abril 2020.doi:10.4103/jfmpc.jfmpc_316_18

16. Alkhotani AM, Almalki WM, Alkhotani AM, Turkistani MA. Makkah female teachers' knowledge of seizure first aid. Epilepsy \& behavior: E\&B, 2019 Sep; (98):10-13. Available from:

https://www.epilepsybehavior.com/article/S15255050(19)30390-7/fulltext. Access on: 20 jun 2020. doi:10.1016/j.yebeh.2019.05.047

17. Alluqmani FA, Omar OM. Assessment of schoolteachers' knowledge about management of traumatic dental injuries in Al-Madinah city, Saudi Arabia. Eur J Dent, 2018; 12(2): 171-75. Available from: https://pubmed.ncbi.nlm.nih.gov/29988212/. Acess on: 20 jun 2020. doi:10.4103/ejd.ejd_38_18

18. Awad MA, AlHammadi E, Malalla M, Maklai Z, Tariq A, Al-Ali B, Al Jameel A, El Batawi H. Assessment of Elementary School Teachers' Level of Knowledge and Attitude regarding Traumatic Dental Injuries in the United Arab Emirates. Int $\mathbf{J}$ Dent. 2017;2017:1025324. . Available from: https://www.ncbi.nlm.nih.gov/pmc/articles/PMC5 618756/. Acess on: 01 jun 2020. doi:10.1155/2017/1025324

19. Taranath M , Senaikarasi RM, Manchanda K. Assessment of knowledge and attitude before and after a health education program in East Madurai primary school teachers with regard to emergency management of avulsed teeth. J Indian Soc Pedod Prev Dent [Internet]. 2017;35(1)63-67. Available from: https://pubmed.ncbi.nlm.nih.gov/28139485/ doi:10.4103/0970-4388.199218

20. Hosapatna M, Bhat N, Prakash J, Sumalatha $\mathrm{S}$, Ankolekar VH. Knowledge and Training of Primary School Teachers in First Aid - A 
Questionnaire Based Study. Kurume Med J [Internet]. 2020; [cited 2021 May 12]; (66):1-5. Available https://pubmed.ncbi.nlm.nih.gov/31941847 doi:10.2739/kurumemedj.MS662001

21. Karimi N, Heidari M. Knowledge and attitudes toward epilepsy among school teachers in West of Iran. Iran $\mathbf{J}$ Neurol [Internet]. 2015;[cited 2021 May 12]; 14(3):130-5. Available from:

https://pubmed.ncbi.nlm.nih.gov/26622977/

22. Attarzadeh H, Kebriaei F, Sadri L, Foroughi E, Taghian M. Knowledge and Attitudes of Elementary Schoolteachers on Dental Trauma and its Management in Yazd, Iran. J Dent (Shiraz). 2017 Sep;18(3):212-218. Available from: https://pubmed.ncbi.nlm.nih.gov/29034277/. Access on: 03 jun 2020.

23. Kolahi AA, Ghorbanpur-Valukolaei M, Abbasi-Kangevari M, Farsar AR. Knowledge, attitudes, and first-aid measures about epilepsy among primary school teachers in northern Iran. Acta Neurol Scand. 2018; [cited 2021 May 12]; 138(1):85-92. Available from: https://onlinelibrary.wiley.com/doi/full/10.1111/a ne.12917 https://doi.org/10.1111/ane.12917

24. Adib-Hajbaghery M, Kamrava Z. Iranian teachers' knowledge about first aid in the school environment. Chin J Traumatol, 2019 Aug; 22(4):240-245. Available from: https://pubmed.ncbi.nlm.nih.gov/31239217/.

Access on: $20 \quad$ ago 2020. doi:10.1016/j.cjtee.2019.02.003

25. Abou Khaled KJ, Ibrahim MI, Moussa RF. Impact of epilepsy training on school teachers and counselors: An intervention study in Lebanon. Epilepsy Behav Rep, 2020 Apr 29; 14:1-6, 100365. Available from: https://pubmed.ncbi.nlm.nih.gov/32435757/.

Access on: $20 \quad$ ago 2020.

doi:10.1016/j.ebr.2020.100365

26. Qureshi FM, Khalid N, Nigah-e-mumtaz S, Assad T, Noreen K. First aid facilities in the school settings: Are schools able to manage adequately? Pakistan J Med Sci [Internet]. 2018; [cited 2021 May 12]; 34(2):272-6. Available from: https://pubmed.ncbi.nlm.nih.gov/29805392/ doi: doi:10.12669/pjms.342.14766

27. Faydali S, Küçük S, Yeşilyurt M. Incidents That Require First Aid in Schools: Can Teachers Give First Aid?. Disaster Med Public Health Prep.2019;13(3): 456-62. Available from: https://pubmed.ncbi.nlm.nih.gov/30047355/. Access on: 13 ago 2020 doi:10.1017/dmp.2018.66

28. Gebrewold MA, Enquselassie F, Teklehaimanot R, Gugssa SA. Ethiopian teachers: Their knowledge, attitude and practice towards epilepsy. BMC Neurol [Internet]. 2016; [cited 2021 May 12]; 16(1):1-8. Available from: http://dx.doi.org/10.1186/s12883-016-0690-4

29. Berhe T, Yihun B, Abebe E, Abera H. Knowledge, attitude, and practice about epilepsy among teachers at Ethio-National School, Addis Ababa, Ethiopia. Epilepsy Behav. 2017 May;70:150-153. . Available from: https://pubmed.ncbi.nlm.nih.gov/28427024/.

\begin{tabular}{llll}
\hline Access on: & 3020.
\end{tabular} doi:10.1016/j.yebeh.2017.02.009

30. Ganfure G, Ameya G, Tamirat A, Lencha B, Bikila D. First aid knowledge, attitude, practice, and associated factors among kindergarten teachers of Lideta sub-city Addis Ababa, Ethiopia. PLoS One [Internet]. 2018; [cited 2021 May 12]; 13(3):1-15. Available from: https://journals.plos.org/plosone/article?id=10.137 1/journal.pone.0194263

https://doi.org/10.1371/journal.pone.0194263

31. Eze CN, Ebuehi OM, Brigo F, Otte WM, Igwe SC. Effect of health education on trainee teachers' knowledge, attitudes, and first aid management of epilepsy: An interventional study. Seizure. 2015 Dec;33:46-53. Available from: https://pubmed.ncbi.nlm.nih.gov/26558347/.

Acess on: 12 jul 2020. doi:10.1016/j.seizure.2015.10.014

32. Elhassan MA, Alemairy AA, Amara ZM, Hamadelneel AA, Mohamed AH, Elaimeri AA. Epilepsy: Knowledge, Attitude, and Practice Among Secondary School Teachers in Khartoum State. Neurol Ther. 2017 Dec;6(2):225-235. Available from: https://pubmed.ncbi.nlm.nih.gov/29063412/doi:10 1007/s40120-017-0083-7. Access on: 12 jul 2020. doi: https://doi.org/10.1007/s40120-0170083-7

33. Antunes LA, Rodrigues AS, Martins AM, Cardoso ES, Homsi N, Antunes LS. Traumatic dental injury in permanent teeth: knowledge and management in a group of Brazilian school teachers. Dent Traumatol. 2016 Aug;32(4):26973. Available from: https://pubmed.ncbi.nlm.nih.gov/26634296/. Acess on: 12 jul 2020 doi:10.1111/edt.12249.

34. Alves LS, Freitas VJ, Rosendo RA, Gominho LF, Sarmento TC.Avaliação do conhecimento de 
professores do ensino fundamental da rede particular sobre atendimento imediato de vítima de traumatismo dental. RFO UPF [online]. 2015; 20(3):302-307. Available from: http://seer.upf. br/index.php/rfo/article/view/4702. Access on: 12 jul 2020. DOI:_https://doi.org/10.5335/ rfo.v20i3.4702

35. Carmo HO, Souza RC, Araújo CL, Francisco AG.Atitudes dos Docentes de Educação Infantil em Situação de Acidente Escolar. RECOM. 2017; 7: 1-7. Available from: http://seer.ufsj.edu.br/index.php/recom/article/vie w/1457/1573. Access on 9 abril 2020, . Doi: http://dx.doi.org/10.19175/recom.v7i0.1457

36. Galindo Neto NM, Carvalho GCN, Castro RCMB, Caetano JA, Santos ECB, Silva TM et al. Teachers' experiences about first aid at school. Rev. Bras. Enferm. [Internet]. 2018 [cited 2021 May 12] ; 71( Suppl 4): 1678-84. Available from:

http://www.scielo.br/scielo.php?script=sci_arttext \&pid=S0034-71672018001001678\&lng=en. https://doi.org/10.1590/0034-7167-2017-0715.

37. Zonta JB, Eduardo AHA, Ferreira MVF, Chaves GH, Okido ACC. Autoconfiança no manejo das intercorrências de saúde na escola: contribuições da simulação in situ. Rev. LatinoAm. Enfermagem [Internet]. 2019 [cited 2021 May 22]; 27: e3174. Available from: http://www.scielo.br/scielo.php?script=sci_arttext \&pid=S0104-11692019000100359\&lng=en.

Epub Oct 07, 2019. https://doi.org/10.1590/15188345.2909.3174.100359\&lng=en. Epub Oct 07, 2019. https://doi.org/10.1590/1518-

8345.2909.3174.

38. Bakarčić D, Hrvatin S, Maroević M, Ivančić Jokić N. First Aid Management in Emergency Care of Dental Injuries - Knowledge among Teachers in Rijeka, Croatia. Acta Clin Croat. 2017 Mar;56(1):110-116. Available from: https://pubmed.ncbi.nlm.nih.gov/29120152/.

Access on: 2 may 2020. doi:10.20471/acc.2017.56.01.16

39. Slabe D, Fink R, Dolenc E, Kvas A. Knowledge of health principles among professionals in Slovenian kindergartens. $\mathrm{Zdr}$ Varst [Internet]. 2016; [cited 2021 May 12]; 55(3):185-94. Available from: https://www.ncbi.nlm.nih.gov/pmc/articles/PMC5 031068 doi:10.1186/s13052-015-0177-8

40. Alba Martín R. Educación para la salud en primeros auxilios dirigida al personal docente del ámbito escolar. Enfermería Univ [Internet]. 2015; [cited 2021 May 12]; 12(2):88-92. Available from: http://dx.doi.org/10.1016/j.reu.2015.04.004

41. Carral San Laureano F, Gutiérrez Manzanedo JV, Moreno Vides P, de Castro Maqueda G, Fernández Santos JR, Ponce González JG, et al. Teachers' attitudes and perceptions about preparation of public schools to assist students with type 1 diabetes. Endocrinol Diabetes y Nutr [Internet]. 2018; [cited 2021 May 12]; 65(4):213-9. Available from: https://www.elsevier.es/en-revista-endocrinologiadiabetes-nutricion-english-ed--413-pdf-

S2530018018300544

https://doi.org/10.1016/j.endien.2018.04.003

42. Abelairas-Gómez C, Carballo-Fazanes A, Martínez-Isasi S, López-García S, Rico-Díaz J, Rodríguez-Núnez A. Conocimiento y actitudes sobre los primeros auxilios y soporte vital básico de docentes de Educación Infantil y Primaria y los progenitores. An Pediatr (Barc), 2020, 92(5): 268$76 . \quad$ Available from: https://analesdepediatria.org/es-pdfS1695403319303698. Access on: 29 abril 2020. doi: https://doi.org/10.1016/j.anpedi.2019.10.010

43. Zunino M, Pantoja MB, Villar AB. Primeros auxilios en la avulsión dentaria. Conocimiento de profesores, entrenadores y padres. 2020; [cited 2021 May 12] 17:65-72. Available from: https://coem.org.es/pdf/publicaciones/cientifica/vo 117num1/Primeros_auxilios_avulsion_dentaria.pd f

44. Kampra M, Tzerakis NG, Losidis S, Katsarou E, Voudris K, Mastroyianni S, et al. Teachers' knowledge about epilepsy in Greece: Information sources and attitudes towards children with epilepsy during school time. Epilepsy Behav [Internet]. 2016; [cited 2021 May 12]; 60:21824. Available from: http://dx.doi.org/10.1016/j.yebeh.2016.04.004

45. Tzimpoulas N, Markou M, Zioutis V, Tzanetakis GN. A questionnaire-based survey for the evaluation of the knowledge level of primary school teachers on first-aid management of traumatic dental injuries in Athens, Greece. Dent Traumatol [Internet]. 2020; [cited 2021 May 22]; 36(1):41-50. Available from: https://onlinelibrary.wiley.com/doi/abs/10.1111/e dt.12503 doi:10.1111/edt.12503

46. Savarese G, Carpinelli L, D’Elia D, Coppola G. Teachers of various school grades and representations of epilepsy: problems, relational aspects and perspectives of life quality. Ital $\mathbf{J}$ Pediatr [Internet]. 2015; [cited 2021 May 12]; 
41(1): $1-5$

Available

from: http://dx.doi.org/10.1186/s13052-015-0177-8

doi:10.1186/s13052-015-0177-8

47. Luckie K, Saini B, Soo YY, Kritikos V, Collins JC, Moles RJ. Impact of scenario based training on asthma first aid knowledge and skills in school staff: an open label, three-arm, parallelgroup repeated measures study. J Asthma [Internet]. 2019; [cited 2021 May 12]; 56(9):973-84. Available from: https://doi.org/10.1080/02770903.2018.1508471

48. Silva DP, Nunes JBB, Moreira RT de F, Costa LC. Primeiros socorros: objeto de educação em saúde para professores. Rev enferm UFPE line [Internet]. 2018; [cited 2021 May 22]; 12(5):1444-53. Available from: https://periodicos.ufpe.br/revistas/revistaenfermag em/article/view/234592/28912\%0Ahttps://periodi cos.ufpe.br/revistas/revistaenfermagem/article/vie $\mathrm{w} / 234592 / 28910$

doi:

https://doi.org/10.1111/j.1600-9657.2010.00897.x

49. Başer, M., Coban, S., Taşci, S., Sungur, G., \& Bayat, M. Evaluating first-aid knowledge and attitudes of a sample of Turkish primary school teachers. Journal of emergency nursing, v. 33, n.5, p. 428-432, 2007. Disponível em: https://www.jenonline.org/article/S0099-

1767(06)00731-8/fulltext. Acesso em: 04 janeiro 2021.

DOI:

https://doi.org/10.1016/j.jen.2006.11.003

50. Dumeier HK, Richter LA, Neininger MP, Prenzel F, Kiess W, Bertsche A, Bertsche T. Knowledge of allergies and performance in epinephrine auto-injector use: a controlled intervention in preschool teachers. Eur J Pediatr. 2018 Apr;177(4):575-581. Disponível em : https://link.springer.com/article/10.1007/s00431017-3073-y. Acesso em : 04 janeiro 2021. doi:10.1007/s00431-017-3073-y

51. Kolahi AA, Ghorbanpur-Valukolaei M, Abbasi-Kangevari M, Farsar AR. Knowledge, attitudes, and first-aid measures about epilepsy among primary school teachers in northern Iran. Acta Neurol Scand. 2018; [cited 2021 May 12]; 138(1):85-92. Available from: https://onlinelibrary.wiley.com/doi/full/10.1111/a ne.12917 https://doi.org/10.1111/ane.12917

52. Salita C, Liwanag R, Tiongco RE, Kawano R. Development, implementation, and evaluation of a lay responder disaster training package among school teachers in Angeles City, Philippines: using Witte's behavioral model. Public Health [Internet]. 2019; [cited 2021 May 12];
170(045):23-31. Available from: https://doi.org/10.1016/j.puhe.2019.02.002 doi:10.1016/j.puhe.2019.02.002

53. Sönmez Y, Uskun E, Pehlivan A. Knowledge levels of pre-school teachers related with basic first-aid practices, Isparta sample. Turk Pediatr Ars [Internet]. 2014; [cited 2021 May 22]; 49(3):238-46. Available from: https://www.ncbi.nlm.nih.gov/pmc/articles/PMC4 462306/pdf/tpa-49-3-238.pdf doi:10.4103/09704388.199218

54. Abdella NHA, Abu-Elenen NRM, Elkazaz RH, Moussa MMM. Intervention program for the kindergarten teachers about pediatrics first aids. American Journal of Research Communication. 2015; 3(5):178-194.

55. Cofano SC, Ojukwu D, Mozumdar N, Raza Z, Saigal S, Musku S, et al Assessing knowledge of symptoms and first-aid care of epilepsy in Grenada, West Indies. Epilepsy Behav. 2017 May;70:232-237. Disponível em: https://www.epilepsybehavior.com/article/S15255050(16)30482-6/fulltext. Acesso em: 14 janeiro 2021. DOI: https://doi.org/10.1016/j.yebeh.2017.03.003

56. Li F, Jiang F, Jin X, Qiu Y, Shen X. Pediatric first aid knowledge and attitudes among staff in the preschools of Shanghai, China. BMC Pediatr [Internet]. 2012; [cited 2021 May 12]; 12:1-7. Available from: https://www.ncbi.nlm.nih.gov/pmc/articles/PMC3 $\underline{447658}$ doi:10.1186/1471-2431-12-121

57. Ali Hossein Mesgarzadeh 1, Mohamdreza Shahamfar AH. Evaluating knowledge and attitudes of elementary school teachers on emergency management of traumatic dental injuries: a study in an Iranian urban area. Oral Heal Prev Dent [Internet]. 2009; [cited 2021 May 12]; 7(n.3):297-308. Available from: https://pubmed.ncbi.nlm.nih.gov/19780438 doi:10.1186/1471-2431-12-121

58. Lima LJ, Filho FJF, Medeiros MO, Nunes GO, Farias MCAD. Epidemiologia Da Epilepsia: Distribuição Brasileira E Global [Internet]. v. 3, Revista Interdisciplinar Encontro Das Ciências. 2020. [cited 2021 May 12]; p. 1368-77. Available from: http://www.riec.fvs.edu.br/index.php/riec/article/v iew/141/119 https://doi.org/10.1000/riec.v3i2.141.g119

59. Noble AJ, Snape D, Ridsdale L, Morgan M, Nevitt SJ, Goodacre S, et al. Assessing treatment fidelity within an epilepsy randomized controlled 
trial: Seizure first aid training for people with epilepsy who visit emergency departments. Behav Neurol [Internet]. 2019; [cited 2021 May 12]; 2019:1-11. Available from: https://pubmed.ncbi.nlm.nih.gov/30863463/ doi: 10.1155/2019/5048794

60. Alves,LS, Freitas VJ, Rosendo RA, Gominho LF, Sarmento TC.Avaliação do conhecimento de professores do ensino fundamental da rede particular sobre atendimento imediato de vítima de traumatismo dental. RFO UPF [online]. 2015; 20(3):302-307. Available from: http://seer.upf. br/index.php/rfo/article/view/4702. Access on: 12 jul 2020.2 DOI: https://doi.org/10.5335/rfo.v20i3.4702

61. Brasil. Ministério da Saúde. Secretaria de Atenção à Saúde. Departamento de Atenção Básica. Saúde na escola / Ministério da Saúde, Secretaria de Atenção à Saúde, Departamento de Atenção Básica. Brasília : Ministério da Saúde, 2009. 96 p.

\section{Autor correspondente}

Danielle Xavier Moraes. Endereço: Avenida

Goiany Prates de Oliveira, Qd.8, LT. 21, nº 1193 , Setor Sul, Trindade, Goiás. CEP: 75391-207.

E-mail:

daniellemoraes@discente.ufg.br/daniellexaviermo raes@gmail.com

Submissão: 2021-08-02

Aprovado: 2021-10-26 